\title{
Updated calibration of the clumped isotope thermometer in planktonic and benthic foraminifera
}

\author{
Peral Marion ${ }^{1,}{ }^{*}$, Daëron Mathieu ${ }^{1}$, Blamart Dominique ${ }^{1}$, Bassinot Franck ${ }^{1}$, Dewilde Fabien ${ }^{1}$, \\ Smialkowski Nicolas ${ }^{1}$, Isguder Gulay ${ }^{1}$, Bonnin Jérôme ${ }^{2}$, Jorissen Frans ${ }^{3}$, Kissel Catherine ${ }^{1}$, \\ Michel Elisabeth ${ }^{1}$, Vázquez Riveiros Natalia ${ }^{1,4}$, Waelbroeck Claire ${ }^{1}$
}

${ }^{1}$ Laboratoire des Sciences du Climat et de l'Environnement, LSCE/IPSL, CEA-CNRS UVSQ, Université Paris-Saclay, F-91191 Gif-sur-Yvette, France

2 Université de Bordeaux, CNRS, Environnements et Paléoenvironnements Océaniques et Continentaux (EPOC), UMR 5805, Allée Geoffroy St Hilaire, 33615 Pessac Cedex, France

${ }^{3}$ UMR CNRS 6112 LPG-BIAF Bio-Indicateurs Actuels et Fossiles, Université d'Angers, 2, Boulevard Lavoisier, 49045 Angers Cedex, France

${ }^{4}$ IFREMER, Laboratoire Géodynamique et enregistrement Sédimentaire, 29280, Plouzané, France

* Corresponding author : Marion Peral, email address : marion.peral@Isce.ipsl.fr

\begin{abstract}
:
Accurate reconstruction of past ocean temperatures is of critical importance to paleoclimatology. Carbonate clumped isotope thermometry (" $\Delta 47$ ") is a relatively recent technique based on the strong relationship between calcification temperature and the statistical excess of $13 \mathrm{C}-18 \mathrm{O}$ bonds in carbonates. Its application to foraminifera holds great scientific potential, particularly because $\Delta 47$ paleotemperature reconstructions do not require assumptions regarding the 180 composition of seawater. However there are still relatively few published observations investigating the potential influence of parameters such as salinity or foraminiferal size and species. We present a new calibration data set based on 234 replicate analyses of 9 planktonic and 2 benthic species of foraminifera collected from recent core-top sediments, with calcification temperatures ranging from -2 to $25^{\circ} \mathrm{C}$. We observe a strong relationship between $\Delta 47$ values and independent, oxygen-18 estimates of calcification temperatures:
\end{abstract}

$\Delta 47=41.63 \times 103 / \mathrm{T} 2+0.2056$

The formal precision of this regression $\left( \pm 0.7-1.0^{\circ} \mathrm{C}\right.$ at $95 \%$ confidence level) is much smaller than typical analytical errors. Our observations confirm the absence of significant species-specific biases or salinity effects. We also investigate potential foraminifer size effects between 200 and $>560 \mu \mathrm{m}$ in 6 species, and conclude that all size fractions from a given core-top location and species display statistically undistinguishable $\Delta 47$ values. These findings provide a robust foundation for future inter-laboratories comparisons and paleoceanographic applications.

Keywords : Carbonate clumped isotopes, foraminifera, paleothermometry 


\section{INTRODUCTION}

The global ocean is a major component of the Earth's climate system because of its role in the redistribution of heat from low to high latitudes. Precisely constraining the physical and chemical characteristics of water masses (temperature and salinity, in particular) is essential to the study of past and present ocean dynamics and climate. For over sixty years, biogenic carbonates such as planktonic and benthic foraminifer shells have provided estimates of sea surface and bottom ocean temperatures based on oxygen isotope carbonate thermometry (Urey, 1947; Epstein et al., 1951; Emiliani, 1966; Shackleton, 1967). A well-known limitation of this classical technique is its sensitivity to the oxygen isotope composition of seawater $\left(\delta^{18} \mathrm{O}_{\mathrm{sw}}\right)$, which in many cases complicates the interpretation of marine $\delta^{18} 0$ records (Shackleton, 1967). Several alternative paleothermometers have been developed over the years to address this issue, either based on organics such as $\mathrm{Uk}^{\mathrm{k}} 37$ (Brassell et al., 1986; Müller et al., 1998; Herbert, 2013) and TEX $_{86}$ (Schouten et al., 2002; Kim et al., 2008, 2010) or based on trace elements in biogenic calcite (e.g., Mg/Ca in foraminifera; Elderfield and Ganssen, 2000; Lea, 2013). However, these alternative proxies have their own limitations, such as the effect of water column recycling, carbonate and sediment diagenesis, sensitivity to the presence of methane, salinity and/or species effect (Mathien-Blard and Bassinot, 2009; Herbert, 2013; Zhang et al., 2016).

Carbonate clumped isotope thermometry is an alternative isotopic technique developed over the past decade (Ghosh et al., 2006; Eiler, 2007; Eiler, 2011). It is based on the quantification of subtle statistical anomalies in the abundance of doubly substituted carbonate isotopologues $\left({ }^{13} \mathrm{C}^{18} \mathrm{O}^{16} \mathrm{O}^{16} \mathrm{O}^{2-}\right)$ relative to a random distribution of isotopes. 
These anomalies may be considered to reflect equilibrium reactions taking place in the aqueous and/or mineral phases, such as:

$$
{ }^{13} \mathrm{C}^{16} \mathrm{O}^{16} \mathrm{O}^{16} \mathrm{O}^{2-}+{ }^{12} \mathrm{C}^{18} \mathrm{O}^{16} \mathrm{O}^{16} \mathrm{O}^{2-} \Leftrightarrow{ }^{13} \mathrm{C}^{18} \mathrm{O}^{16} \mathrm{O}^{16} \mathrm{O}^{2-}+{ }^{12} \mathrm{C}^{16} \mathrm{O}^{16} \mathrm{O}^{16} \mathrm{O}^{2-}
$$

For fundamental physical reasons, the right-hand side of this reaction is thermodynamically favoured, and the corresponding equilibrium constant varies with temperature (Schauble et al., 2006). As a result, carbonate minerals precipitated under conditions close to isotopic equilibrium are expected to contain a slightly higher abundance of ${ }^{13} \mathrm{C}-18 \mathrm{O}$ bonds than that predicted for a stochastic distribution of isotopes. This statistical anomaly should decrease systematically with crystallization temperature, and may be preserved over geologic time scales in the absence of diagenesis and solid-state redistribution of isotopes (Eiler 2011; Passey and Henkes, 2012; Stolper and Eiler, 2016). The conversion of carbonate to $\mathrm{CO}_{2}$ by phosphoric acid reaction (McCrea, 1950) also preserves this signal, so that the calcification temperature can be estimated by precisely measuring $\Delta_{47}$, defined as the statistical overabundance of mass-47 $\mathrm{CO}_{2}$ (Ghosh et al., 2006). An important difference between the oxygen-18 and clumped-isotope thermometers is that the latter does not require any assumption to be made about the oxygen isotope composition of the aqueous phase.

Over the past decade, a number of calibration studies have investigated the relationship between $\Delta_{47}$ and temperature in inorganic carbonates (Ghosh et al., 2006; Dennis and Schrag, 2010; Zaarur et al., 2013; Tang et al., 2014; Defliese et al., 2015; Kele et al., 2015; Kluge et al., 2015; Tripati et al., 2015; Bonifacie et al., 2017; Kelson et al., 2017; Breitenbach et al., 2018; Levitt et al., 2018) and biogenic carbonates such as corals, otoliths, brachiopods, molluscs, foraminifera and coccoliths (Ghosh et al., 2006; Tripati et al., 2010; Thiagarajan et al., 2011; Zaarur et al., 2011; Eagle et al., 2013; Grauel et al., 2013; Came et al., 2014; Douglas et al., 2014; Wacker et al., 2014; Katz et al., 2017). Only 
two of these calibrations specifically focus on foraminifera: the finding by Tripati et al. (2010) that different foraminiferal species appear to follow a single relationship between temperature and $\Delta_{47}$ was subsequently confirmed by Grauel et al. (2013). These early calibration studies produced a significant body of observations whose importance should not be understated. However, both of them predate substantial methodological advances in the field of clumped isotope measurements, namely the definition by Dennis et al. (2011) of an "absolute" reference frame anchored to theoretical equilibrium $\Delta_{47}$ values in $\mathrm{CO}_{2}$ (although Grauel et al. published their observations in 2013, their analyses were performed earlier and the results are reported in the older $\Delta_{47}$ reference frame), and the systematic distribution of interlaboratory carbonate standards. As a result, using these early observations to precisely reconstruct past seawater temperatures is not straightforward.

Here, we present new calibration data for $\Delta_{47}$ in foraminifera covering a wide range of temperatures $\left(-2{ }^{\circ} \mathrm{C}\right.$ to $\left.25{ }^{\circ} \mathrm{C}\right)$ that are relevant to paleoceanographic studies. We first compare the potential chemical and isotopic impact of the sample cleaning protocols used in previous studies. We then investigate different strategies for obtaining $\Delta_{47^{-}}$ independent constraints on calcification temperatures. Finally, we focus on the possible influence of salinity, and potential biases associated with foraminifer size and species.

\section{MATERIALS AND METHODS}




\subsection{Samples}

Twelve sedimentary core-tops from the North Atlantic, Austral and Pacific basins (Figure 1 and Table 1) were selected based on their abundance of foraminifera. We targeted 9 planktonic and 2 benthic species, covering a wide temperature range, from $2{ }^{\circ} \mathrm{C}$ to $25{ }^{\circ} \mathrm{C}$. Individual foraminifera were hand-picked in different size fractions from 200 to $560 \mu \mathrm{m}$. We hereafter define each sample as a unique combination of core-top, species and size fraction. From each of these 58 samples, we used between 16 and $20 \mathrm{mg}$ of foraminifera for stable isotope analyses $\left(\Delta_{47}, \delta^{18} \mathrm{O}, \delta^{13} \mathrm{C}\right)$.

All core-tops were chronologically constrained following the MARGO recommendations (Kucera et al., 2005) and correspond to Late Holocene ages (0-4 ka, Table 1). Age intervals were determined by AMS (Accelerator Mass Spectrometry) radiocarbon dating, by the presence of Rose Bengal stained foraminifera (alive at the time of collection or shortly before it; Walker et al., 1974) implying recent sediments, or by external stratigraphic controls (e.g., $\delta^{18} \mathrm{O}$ stratigraphy). New ${ }^{14} \mathrm{C}$ dating supporting the present study was performed on monospecific foraminiferal shells at the UMS-ARTEMIS facility (CNRS-CEA, Saclay, France), using a Pelletron 3 MV AMS. Radiocarbon analyses were performed following the standard procedure described by Tisnérat-Laborde et al. (2001). Uncalibrated radiocarbon ages were converted to calendar ages using the calib7.1 software (Stuiver et al., 2017) and the marine-13 calibration dataset (Reimer et al., 2013), with reservoir age corrections depending on core-top locations (Table 1).

\subsection{Sample pre-treatment}


The top $10 \mathrm{~mm}$ of sediment from each core-top were collected and dried overnight at $50{ }^{\circ} \mathrm{C}$. The samples were wet sieved to collect the size fraction larger than $150 \mu \mathrm{m}$. The foraminifera were then hand-picked from different size fractions between 200 and $>560 \mu \mathrm{m}$ (Table 2). Foraminifer shells were cleaned to eliminate organic and detrital contaminants. Following the approach of Grauel et al. (2013), we tested two cleaning procedures based on earlier foraminifer $\Delta_{47}$ calibration studies (Tripati et al., 2010; Grauel et al., 2013, respectively protocol \#1 and protocol \#2 hereafter). Both cleaning procedures require the following initial steps:

- Gently crush foraminifera between two glass slides to open all chambers;

- Rinse the foraminifer fragments at least twice with ultrapure water in an ultrasonic bath for one minute (repeat if necessary, until the water remains clear and colourless);

- $\quad$ Rinse twice with reagent-grade methanol in an ultrasonic bath for 30 seconds.

In the original protocol (\#1) of Tripati et al. (2010), a final step required adding a cold dilute solution of $1 \% \mathrm{H}_{2} \mathrm{O}_{2}$, to remove possible organic contaminants. Grauel et al. (2013) used instead a $10 \% \mathrm{H}_{2} \mathrm{O}_{2}$ buffered at $\mathrm{pH} 8$ with a phosphate solution. In the present study we used $1 \% \mathrm{H}_{2} \mathrm{O}_{2}$ with a sodium hydroxide buffer in an attempt to minimize potential alteration of the original bio-carbonate. Scanning Electron Microscopy (SEM) images acquired at the GEOPS laboratory (Figure 2) and stable and clumped isotope analyses (Figure 3, Table S1 in supplementary material) were used to compare the effects of both protocols and to test their ability to remove all traces of ethanol and Rose Bengal. SEM images of uncleaned shells reveal the presence of numerous coccoliths and detrital grains adhering to the shell surface (Figure 2a). Protocol \#2 (Figure 2b) successfully removes such incrusted contaminants, exposing well-preserved foraminiferal calcite. Conversely, protocol \#1 (Figure 2c) produces 
visible dissolution and recrystallization features to the shell fragments. Based on these optical observations, protocol \#2 seems to yield optimal preservation of the initial state of the foraminiferal tests. Carbon-13, oxygen-18 and clumped isotope measurements were also performed on the cleaned samples to assess potential isotopic effects (Figure 3). No significant differences in $\delta^{18} 0, \delta^{13} \mathrm{C}$ and $\Delta_{47}$ values were observed between foraminifera treated with the two protocols (Figure 3a.b). Additionally, the same test was performed on foraminifera that had been soaked beforehand for 15 days in ethanol (Figure 3c.d) and in a mixture of ethanol and Rose Bengal (Figure 3e.f). Again, all stable isotope analyses were found to yield statistically undistinguishable values after cleaning with either protocol. Based on the observations summarized above, and because none of our calibration samples comes from environments with high organic productivity such as upwelling regions, we decided to avoid the potentially destructive oxidative step of protocol \#1 and cleaned all of our calibration samples by following protocol \#2.

\subsection{Analytical methods}

\subsection{1. $\Delta_{47}$ measurements}

A total of 361 clumped-isotope analyses were performed at the Laboratoire des Sciences du Climat et de l'Environnement (LSCE) using the same equipment and procedures as those described by Daëron et al. (2016). Carbonate samples weighing between 2 and $3 \mathrm{mg}$ were dissolved in a common phosphoric acid bath at $90^{\circ} \mathrm{C}$ for 15 minutes. After cryogenic removal of water, the evolved $\mathrm{CO}_{2}$ passed through a Porapak $\mathrm{Q}$ column (50/80 mesh, $1 \mathrm{~m}$ length, $2.1 \mathrm{~mm}$ ID) held at $-20^{\circ} \mathrm{C}$ under helium 6.0 flow (25 $\mathrm{mL} / \mathrm{min}) . \mathrm{CO}_{2}$ was then quantitatively recollected by cryogenic trapping, and 
transferred by gas expansion into an Isoprime 100 dual-inlet mass spectrometer equipped with six Faraday collectors (m/z 44 to 49). Each analysis took about 3 hours, during which sample gas and working reference gas were allowed to flow from matching, $10 \mathrm{~mL}$ reservoirs into the source, through a pair of fused silica capillaries (65 cm length, $110 \mu \mathrm{m}$ ID). Every 20 minutes, gas pressures were adjusted to achieve a mass 44 current of $40 \mathrm{nA}$, with differences between sample and reference gas generally below $0.1 \mathrm{nA}$. Background currents were measured in all high-gain collectors (m/z 45 to 49) before and after each pressure adjustment, with gas flowing into the source, and are found to strongly correlate with mass 44 current.

Background-corrected ion current values were processed using the IUPAC isotopic parameters (Brand et al., 2010) to compute $\delta^{13} C_{\mathrm{VPDB}}, \delta^{18} \mathrm{O}_{\mathrm{VPDB}}$ and $\Delta_{47}^{\mathrm{raw}}$ values for each analysis. The isotopic composition $\left(\delta^{13} \mathrm{C}, \delta^{18} \mathrm{O}\right)$ of our working reference $\mathrm{CO}_{2}$ was computed based on nominal $\delta^{13} \mathrm{CVPDB}_{\mathrm{VP}} \delta^{18} \mathrm{O}_{\mathrm{VPDB}}$ values for carbonate standard ETH-3 $\left(\delta^{13} \mathrm{C}_{\mathrm{VPDB}}=1.71 \%\right.$, $\delta^{18} \mathrm{OVPDB}_{\mathrm{VP}}=-1.77 \%$, recomputed by Bernasconi et al., in review $)$ and an oxygen-18 acid fractionation factor of 1.008176 (Das Sharma et al., 2002).

Four carbonate standards, ETH-1 to ETH-4 (Meckler et al., 2014; Bernasconi et al., in review), were then used to convert $\Delta_{47}^{\mathrm{raw}}$ to absolute $\Delta_{47}$ values, following the procedure described by Daëron et al. (2016). The nominal $\Delta_{47}$ values for these standards are those recomputed by Bernasconi et al. (in review) using IUPAC parameters, respectively 0.258 \%o for ETH-1, 0.256 \%o for ETH-2, 0.691 \% for ETH-3 and 0.507 \%o for ETH-4.

\subsubsection{Traditional stable isotope measurements}

Traditional oxygen and carbon stable isotope analyses were also performed for each sample (defined above as a unique combination of core-top species and size fraction). 
An average of 20-30 planktonic and 5 benthic foraminifer tests were hand-picked for each replicate analysis, with at least 4 replicates per sample (see supplementary material, Table S2). Foraminifera were then cleaned in an ultrasonic bath of reagentgrade methanol for a few seconds to eliminate impurities (Duplessy, 1978 without the roasting step). $\delta^{18} \mathrm{O}_{\mathrm{VPDB}}$ and $\delta^{13} \mathrm{C}_{\mathrm{VPDB}}$ values were measured at LSCE using three intercalibrated mass spectrometers (a GV-Isoprime, an Isoprime 100 and a VG-Optima) and standardized to VPDB using NBS-19 and NBS-18 carbonate standards (Coplen, 1996). For NBS-19, assigned values are: $\delta^{18} \mathrm{O}_{\mathrm{VPDB}}=-2.20 \%$ and $\delta^{13} \mathrm{C}_{\mathrm{VPDB}}=1.95 \%$ and for NBS-18, designated values are: $\delta^{18} \mathrm{O}_{\mathrm{VPDB}}=-23.01 \pm 0.10 \%$ and $\delta^{13} \mathrm{C}_{\mathrm{VPDB}}=-5.01 \pm$ $0.03 \%$. The uncertainties reported here for traditional stable isotope measurements are based on the external reproducibility of in-laboratory carbonate standards, with 1SD $=0.05 \%$ for $\delta^{18} \mathrm{O}_{\mathrm{VPDB}}$ and $1 \mathrm{SD}=0.03 \%$ for $\delta^{13} \mathrm{C}_{\mathrm{VPDB}}$.

\subsection{Independent constraints on calcification temperatures}

Two alternative approaches to estimate the calcification temperatures of foraminifera were considered. The first one relies on the World Ocean Atlas temperature database (WOA13, Locarnini et al., 2013, https://www.nodc.noaa.gov/OC5/woa13), and the second one is based on "isotopic" temperatures estimated by combining foraminifer $\delta^{18} \mathrm{O}$ measurements with the local oxygen-isotope composition of seawater $\left(\delta^{18} \mathrm{O}_{\mathrm{sw}}\right)$ derived from the Global Seawater Oxygen-18 Database (LeGrande and Schmidt, 2006, https://data.giss.nasa.gov/o18data).

\subsubsection{WOA13 temperatures}


For benthic foraminifera, we extracted the mean annual bottom temperature at each core location (field "t_an" in the WOA13-V2 dataset), with uncertainties corresponding to the standard deviation values given by the interpolation in the WOA13 dataset.

For planktonic foraminifera, we calculated the average water column temperature over a range of calcification depths depending on species and core-top location. According to Tolderlund and Bé (1971) and Durazzi (1981), calcification depths in the North Atlantic Ocean correspond to 0-10 m for G. ruber. For G. bulloides, O. universa, G. truncatulinoides, G. inflata, G. menardii, and N. pachyderma, the depths associated are comprised between 0 and $300 \mathrm{~m}$. In the Indian Ocean, Duplessy et al. (1981) placed the depth of calcification for all these species within and below the mixed layer, except for G. ruber and $G$. menardii which are believed to remain respectively at the surface and within the mixed layer (0-200 m). In the South China Sea, G. ruber and G. menardii are described as living near the surface and in the top 200 m, respectively (Pflaumann and Jian, 1999). Finally, the living depth of $O$. universa being very poorly constrained to the best of our knowledge, we assume that it lives at the same depth as $G$. menardii, by analogy with the North Atlantic Ocean. Furthermore, the seasonality of phytoplankton blooms remains poorly constrained in the literature. We thus followed a conservative approach by averaging the monthly mean temperatures of summer, spring and fall (excluded December, January and February) for each core, with assigned uncertainties reflecting both seasonal and vertical variability, quantified as the standard deviation of all temperature data for a given site, with a monthly temporal resolution and a uniform depth resolution of one meter over the range of (species-dependent) living depths.

\subsubsection{Isotopic temperatures}


In an attempt to reduce the uncertainties related to our assumptions on the calcification depth and seasonality of each species, we compared the WOA13 temperatures to oxygen isotope temperature estimates, derived from either one of two equations: Shackleton (1974) modified by $0.27 \%$ (Hut, 1987) to express seawater and carbonate $\delta^{18} 0$ values relative to VSMOW and VPDB, respectively (equation 1), and Kim and O'Neil (1997) modified for consistency with the use of an acid fractionation factor of 1.01025 (equation 2)

$\mathrm{T}=16.9-4,38 \times\left(\delta^{18} \mathrm{O}_{\mathrm{C} / \mathrm{VPDB}}-\delta^{18} \mathrm{O}_{\mathrm{SW} / \mathrm{VSMOW}}+0.27\right)+0.10 \times\left(\delta^{18} \mathrm{O}_{\mathrm{C} / \mathrm{VPDB}}-\delta^{18} \mathrm{O}_{\mathrm{SW} / \mathrm{VSMOW}}+\right.$ $0.27)^{2} \quad$ (equation 1)

Where $\mathrm{T}$ is the isotopic temperature in ${ }^{\circ} \mathrm{C}$ and $\delta^{18} \mathrm{O}_{\mathrm{C} / \mathrm{VPDB}}$ and $\delta^{18} \mathrm{O}_{\text {sw/vsmow }}$ are the $\delta^{18} \mathrm{O}$ of the foraminiferal calcite relative to VPDB and of the seawater relative to VSMOW, respectively. Following Marchitto et al. (2014), Cibicides $\delta^{18} 0$ were adjusted to the Uvigerina scale by $0.47 \%$.

$$
\left.1000 \ln \left(\alpha_{\mathrm{cc} / \mathrm{w}}\right)=18.03 \times 1000 / \mathrm{T}-32.17 \quad \text { (equation } 2\right)
$$

Where $\mathrm{T}$ is temperature in $\mathrm{K}$ and $\alpha_{\mathrm{cc} / \mathrm{w}}$ is the oxygen-18 fractionation factor between calcite and water: $\alpha_{\mathrm{cc} / \mathrm{w}}=\left(1+\delta^{18} \mathrm{O}_{\mathrm{C} / \mathrm{Smow}} / 1000\right) /\left(1+\delta^{18} \mathrm{O}_{\text {sw/Smow }} / 1000\right)$ with $\delta^{18} \mathrm{O}_{\mathrm{C} / \mathrm{SMOW}}$ and $\delta^{18} \mathrm{O}_{\mathrm{SW} / \mathrm{Smow}}$ corresponding to foraminiferal calcite and seawater, respectively, both relative to VSMOW. Again, following the recommendation of Marchitto et al. (2014), $\delta^{18} \mathrm{O}_{\mathrm{c}}$ values for Uvigerina were adjusted by subtracting $0.47 \%$. It is well know that different planktonic foraminifer species from the same core may yield different $\delta^{18} \mathrm{O}_{\mathrm{C}}$ values due to differences in depth and seasonality calcification (e.g. 
Mix, 1987; Ortiz et al., 1995; Schiebel, 2002; Mortyn and Charles, 2003; Jonkers and Kurcera, 2015). Precise characterization of these species-specific effects is still very much an open issue. However, the FAME (Foraminifera As Modeled Entities) model recently developed by Roche et al. (2017) implies that, assuming that planktonic foraminifera follow the oxygen-18 fractionation law of Kim \& O'Neil (1997), variations in calcification depth and seasonality provide a good first-order prediction for $\delta^{18} \mathrm{O}_{\mathrm{c}}$ values, with root mean square residuals on the order of $0.2 \%$ for G. ruber, G. bulloides, and N. pachyderma. These residuals are similar to the errors we assigned to our $\delta^{18} \mathrm{O}_{\text {sw }}$ values (see below), which dominate the uncertainties in our isotopic temperature estimates. For this reason, no species-specific adjustments were applied to our planktonic samples.

Seawater $\delta^{18} 0$ values at each core site were extracted from the gridded data set of LeGrande and Schmidt (2006). For benthic foraminifera, we only considered bottom $\delta^{18} \mathrm{O}_{\text {sw }}$ values. Because of the poor constraints on calcification depths for planktonic species (see above), we compared mean $\delta^{18} \mathrm{O}_{\text {sw }}$ values averaged over 0-50 m and 0-500 $\mathrm{m}$ (see supplementary Table S3). The differences in mean $\delta^{18} 0$ sw between these two depth ranges are on the order of $0.03 \pm 0.08 \%$, indicating that the choice of water depth is not critical for our core sites. We have thus considered averaged $\delta^{18} \mathrm{O}_{\text {sw }}$ between 0 and $500 \mathrm{~m}$. The uncertainties in $\delta^{18} \mathrm{O}_{\mathrm{sw}}$ for each core site were defined as the quadratic sum of the site-specific standard deviation of $\delta^{18} \mathrm{O}_{\mathrm{sw}}$ within the top $500 \mathrm{~m}$ of the water column and a constant error of $0.20 \%$ assigned to the GISS grid interpolation. To the best of our knowledge, the true uncertainties in the gridded values of LeGrande and Schmidt have not been quantified, but we believe that our arbitrary choice of $0.20 \%$ is conservative. Final uncertainties on the isotopic temperatures are 
propagated based on the $\delta^{18} \mathrm{O}_{\mathrm{sw}}$ uncertainties assigned above and the (external) analytical error on $\delta^{18} \mathrm{O}_{\mathrm{c}}$ values.

\section{RESULTS}

The complete results for each foraminifer and standard carbonate analysis are provided in Table S4 (supplementary material). The measurements were performed over the course of five independent analytical sessions from May 2015 to September 2017.

Table 2 summarizes $\Delta_{47}$ and $\delta^{18} \mathrm{O}_{\mathrm{c}}$ values of all samples for which at least 4 different size fractions were analysed. The mean results for all samples grouped by species and coretop are reported in Table 3, together with the estimated foraminifera calcification depth and $\delta^{18} \mathrm{O}_{\mathrm{sw}}$, and the three different estimates of calcification temperatures defined in section 2.4. Mean $\Delta_{47}$ values range from 0.669 to $0.769 \%$. The lowest $\Delta_{47}$ values were observed in G. ruber (MD02-2577) at an estimated temperature from Equation 2 of 25.1 $\pm 1.1{ }^{\circ} \mathrm{C}$ and the highest in C. wuellerstorfi (MOCOSED) at $-1.6 \pm 0.8^{\circ} \mathrm{C}$.

\subsection{External reproducibility of $\delta^{13} \mathrm{C}, \delta^{18} \mathrm{O}$ and $\Delta_{47}$ measurements}

Clumped isotope analyses require measuring the $\delta^{13} \mathrm{C}$ and $\delta^{18} \mathrm{O}$ values of each sample. We compared these values to those obtained from traditional IRMS methods. The two methods yield statistically indistinguishable results (see supplementary material Figure S1). All $\delta^{13} \mathrm{C}$ and $\delta^{18} \mathrm{O}$ values considered hereafter are those obtained as part of the clumped isotope analyses. 
We can assess the long-term analytical reproducibility of our isotopic measurements based on repeated analyses of the ETH standards:

$$
\sigma^{2}=\frac{\sum\left(x_{r}-\overline{x_{s}}\right)^{2}}{N_{r}-N_{s}}
$$

where $\sigma$ is an aggregate estimate of long-term reproducibility, $x_{r}$ are the values from each replicate measurement of all standards, $\overline{x_{s}}$ is the average value for the corresponding standard, $\mathrm{N}_{\mathrm{r}}$ is the total number of standard replicate analyses $\left(\mathrm{N}_{\mathrm{r}}=127\right)$ and $\mathrm{N}_{\mathrm{s}}$ is the number of standards considered $\left(\mathrm{N}_{\mathrm{s}}=4\right)$. The $\sigma$ statistic is computed in the same way for $\delta^{13} C_{V P D B}, \delta^{18} O_{V P D B}$ and $\Delta_{47}$, yielding external reproducibilities of $0.032 \%$, $0.084 \%$ and $0.0166 \%$, respectively.

We may also compute $\sigma$ for all of our calibration samples instead of the ETH standards, which yields a slightly improved $\Delta_{47}$ reproducibility of $0.0135 \%$ and comparable reproducibilities for $\delta^{13} \mathrm{C}$ and $\delta^{18} 0$. Computing combined $\sigma$ values taking into account all standards and calibration samples, the final external error assigned to each of our $\Delta_{47}$ replicate measurements is $0.0148 \%$.

\section{DISCUSSION}

\subsection{Foraminifera $\Delta_{47}$ versus size effect}

In order to investigate potential size effects on measured $\Delta_{47}$ values, we considered six foraminiferal species for which we have at least 4 different size fractions (Figure 4, Table S4). The corresponding $\Delta_{47}$ and $\delta^{18} 0_{\mathrm{C}}$ values are listed in Table 2. All measurements within each species are statistically indistinguishable, with the single exception of $\delta^{18} \mathrm{O}_{\mathrm{C}}$ values for Globorotalia inflata, which vary over a range of $0.8 \%$ 
(Figure 4). Although the corresponding $\Delta_{47}$ values remain statistically indistinguishable from each other, they nevertheless appear to be positively correlated with $\delta^{18} \mathrm{O}_{\mathrm{C}}$ (Pearson correlation coefficient $=0.79$ ), consistent with the hypothesis that the observed isotopic differences between different size fractions of $G$. inflata reflect different calcification temperatures that may be due to seasonality or depth habitats. For this species, we thus decided to treat each size fraction as an individual sample with its own calcification temperature constrained by its $\delta^{18} \mathrm{O}_{\mathrm{C}}$.

Our observations do not strictly rule out potential foraminifer size biases, but they imply that such biases must be smaller than what can be resolved with the typical $\Delta_{47}$ precision we obtain from 4 analytical replicates ( $S E=7-8 \mathrm{ppm}$ ). The absence of detectable size effect implies that we may combine the isotopic results from all size fractions (excluding G. inflata). From a practical point of view, this greatly facilitates picking enough material for a large number of replicates.

\subsection{Assignment of independent temperature constraints}

Figure 5 a shows a comparison between temperatures estimated from WOA13, and the isotopic temperatures derived from equation 2 (Kim and O’Neil, 1997). The two methods are generally in poor agreement, with discrepancies from $0.2{ }^{\circ} \mathrm{C}$ to $6{ }^{\circ} \mathrm{C}$ affecting many of our samples. These discrepancies are most likely related to the assumptions that had to be made regarding the calcification depth of each species. This would be consistent with past studies which argued that foraminifera species may occupy water depth ranges more variable than traditionally assumed, and that habitat depth may vary significantly from one location to another (Mortyn and Charles, 2003; Simstich et al., 2003). Because local $\delta^{18} \mathrm{O}_{\text {sw }}$ values vary much less with depth and 
seasonality than water temperature does, it is reasonable to expect that isotopic estimates of calcification temperatures are less sensitive to assumptions of calcification depth and seasonality. It should be noted that the uniformity of $\delta^{18} \mathrm{O}_{\mathrm{sw}}$ values from the gridded interpolation does not result from a paucity of observations but from the uniformity in WOA salinity values (LeGrande and Schmidt, 2006).

In Figure 5b, we compare the isotopic temperatures obtained using equation 1 (Shackleton, 1974) and equation 2 (Kim and O’Neil, 1997). Unsurprisingly, the two equations yield different but highly correlated temperature estimates, with differences gradually decreasing from low to high temperatures. These differences range from $2{ }^{\circ} \mathrm{C}$ to $1.5{ }^{\circ} \mathrm{C}$ for the lowest temperatures $\left(<9^{\circ} \mathrm{C}\right)$ and remain below $1{ }^{\circ} \mathrm{C}$ to $0.5{ }^{\circ} \mathrm{C}$ for temperatures above $25{ }^{\circ} \mathrm{C}$. Whereas the calibration of Shackleton (1974) covers a restricted temperature range corresponding to benthic foraminifera $\left(<7^{\circ} \mathrm{C}\right)$, that of Kim and O'Neil (1997) covers a larger temperature range, potentially applicable to benthic and planktonic foraminifera. We thus decided to use the oxygen isotopic temperatures from Equation 2.

\subsection{Relationship between temperature and $\Delta_{47}$}

Based on the absence of detectable foraminifer size effect demonstrated in section 4.1, we may average the replicates measurements of $\Delta_{47}$ obtained for samples differing only in size fraction, and all replicate measurements of $\delta^{18} \mathrm{O}_{\mathrm{C}}$ (excluding $G$. inflata) to compute the estimates of calcification temperatures, from equation 2 . This results in 28 calibration data points corresponding to different species and core-top location (Figure 6 and Table 3). 
Mean $\Delta_{47}$ values for these 28 samples strongly correlate with ${ }^{18} \mathrm{O}$-derived estimates of calcification temperature. The standard errors associated with these 28 data points range from 2.7 to $8.5 \mathrm{ppm}$ for $\Delta_{47}$ and from 0.4 to $0.7^{\circ} \mathrm{C}$ for temperature, implying that both variables significantly contribute to the uncertainties of the regression. We thus compute the total least squares regression of $\Delta_{47}$ on $1 / \mathrm{T}^{2}$ (with $\mathrm{T}$ in $\mathrm{K}$ ) using the formulation of York et al. (2004).

An examination of the fit residuals (Figure 6) suggests that the data point associated with sample MD88-770-G. bulloides might be a statistical outlier, defined as an anomalous observation very unlikely to result from statistical error alone. Grubbs' test for a single outlier (Grubbs, 1969; Stefansky, 1972) rejects the null hypothesis of no outliers at a 95\% significance level $(\mathrm{p}=0.026)$. This anomaly is unlikely to result from an isotopic effect specific to G. bulloides, because the four other samples of the same species have all statistically null residuals. However, core MD88-770 is located near the boundary between two of the salinity/oxygen-18 regions used to produce the gridded $\delta^{18} \mathrm{O}_{\text {sw }}$ values of LeGrande and Schmidt (2006), implying that the seawater oxygen isotope values which we assigned to this particular sample are poorly constrained. Furthermore, variations in the position of the polar front between the Indian and Austral Oceans cause $\delta^{18} \mathrm{O}_{\mathrm{sw}}$ values to vary seasonally. We thus conclude a posteriori that we cannot reliably assign an isotopic temperature to this data point, and hereafter exclude it from the calibration data set. However, we note that the WOA13 temperature for MD88-770-G. bulloides is $11.1 \pm 1.5^{\circ} \mathrm{C}$, which would place this sample only $0.011 \pm$ 0.007 (1SE) \%o above the new regression line (Figure 6).

Recomputing the total least squares regression (Figure 6) yields the following relationship: 


$$
\left.\Delta_{47}=41.63 \times 10^{3} / \mathrm{T}^{2}+0.2056 \quad \text { (Equation } 3\right)
$$

In order to assess goodness of fit, we may compute the reduced chi-squared statistic, also known as mean square weighted deviation (MSWD):

$$
M S W D=\frac{1}{N_{S}-2} \sum_{i} \frac{\left(Y_{i}-A X_{i}-B\right)^{2}}{\sigma_{Y i}^{2}+A^{2} \sigma_{X i}^{2}}
$$

where $X_{i}$ and $Y_{i}$ are the observations (respectively $1 / T^{2}$ and $\Delta_{47}$ ), with corresponding standard errors $\sigma_{X i}$ and $\sigma_{Y i}$, and $\mathrm{N}_{\mathrm{s}}=27$ is the number of observations. Note that our $\left(\mathrm{X}_{\mathrm{i}}\right.$, $\mathrm{Y}_{\mathrm{i}}$ ) observations are not fully independent from each other, because $\Delta_{47}$ values are anchored to a shared set of carbonate standard measurements, and because estimated $\delta^{18} \mathrm{O}_{\mathrm{sw}}$ values for samples from the same core-top should be highly correlated. We thus only use the MSWD as a qualitative indicator of goodness-of-fit. Our regression model yields a MSWD of 0.82 , suggesting that our assigned uncertainties may be slightly overestimated compared to the scatter observed in our results.

Computing the formal standard errors for this regression is not straightforward because the slope and intercept values of equation 3 are strongly anti-correlated, and calculations taking their covariance into account are sensitive to rounding errors. We may, however, reformulate Equation 3 in terms of the barycentre of our $\left(1 / \mathrm{T}_{0}{ }^{2}\right)$ values:

$$
\begin{gathered}
\Delta_{47}=\mathrm{A} \times 10^{3}\left(1 / \mathrm{T}^{2}-1 / \mathrm{T}_{0}{ }^{2}\right)+\mathrm{B} \\
\mathrm{A}=41.63 \pm 0.84(1 \mathrm{SE}) \\
\mathrm{B}=0.7154 \pm 0.0011(1 \mathrm{SE}) \\
\mathrm{T}_{0}=12.61{ }^{\circ} \mathrm{C}
\end{gathered}
$$


Using this new formulation, parameters A and B are now independent, and the standard error of our regression model is simply expressed as:

$$
\sigma^{2}\left(\Delta_{47}\right)=\sigma^{2}(\mathrm{~A})\left(1 / \mathrm{T}^{2}-1 / \mathrm{T}_{0}^{2}\right)^{2}+\sigma^{2}(\mathrm{~B})
$$

Based on this formulation, the $95 \%$ confidence limits of our regression model range from $\pm 0.7{ }^{\circ} \mathrm{C}$ to $\pm 1{ }^{\circ} \mathrm{C}$ between $-2{ }^{\circ} \mathrm{C}$ and $25^{\circ} \mathrm{C}$. As a result, the precision of absolute temperature reconstructions based on equation 3 will generally be limited by errors in $\Delta_{47}$ measurements (including any inter-laboratory biases) rather than by our regression errors. For instance, in the hypothetical case of repeated $\Delta_{47}$ measurements of a single sample with an external reproducibility of $0.015 \%$, between 50 and 90 replicate analyses would be required to reach $95 \%$ confidence limits of $\pm 1{ }^{\circ} \mathrm{C}$.

\subsection{Species-specific effects on foraminiferal $\Delta_{47}$}

Figure 7 shows the $\Delta_{47}$ regression residuals for our calibration samples labelled by habitat depth (benthic, surface or thermocline). Excluding the single outlier discussed above, the surface-dwelling species (G. ruber) is statistically indistinguishable from the thermocline- and deep-dwelling species (N. pachyderma, G. menardii, O. universa, G. inflata and G. truncatulinoides, G. bulloides). The two benthic species, U. mediterranea and C. wuellerstorfi, are in excellent agreement with the overall regression model, despite the well-established observation that they appear to follow different oxygen-18 fractionation laws.

The absence of species effect on $\Delta_{47}$ among the planktonic and benthic foraminifera investigated here, is consistent with the findings of Tripati et al. (2010) and Grauel et al. 
(2013), and suggests that the above calibration relationship may be applicable to most foraminifera.

\subsection{Foraminiferal $\Delta_{47}$ versus salinity effect}

Seawater salinity values at each core-top location were extracted from the gridded data set of WOA13 (Zweng et al., 2013). As we did with the GISS $\delta^{18} \mathrm{O}_{\text {sw }}$ values, (section 2.4.2, supplementary Table S3), we compared the average salinity over 0-50 m and 0-500 m depths. As for $\delta^{18} \mathrm{O}_{\text {sw }}$ values, average salinities at our core-top locations are not sensitive to the choice of the depth interval, so we compute average salinity values over the top $500 \mathrm{~m}$ of the water column. Uncertainties were estimated at each core-top site as the quadratic sum of a nominal error of 0.20 psu arbitrarily assigned to the WOA13 data set and the site-specific standard deviation of salinity over the top $500 \mathrm{~m}$ of the water column.

Our samples cover a salinity range from 34 to $36 \mathrm{psu}$, which corresponds to the typical salinity values of the world ocean. As shown in Figure 8a, no correlation is detectable between $\Delta_{47}$ residuals and salinity. Mathematically, this could conceivably result from a strong covariation of temperature and salinity at our core-top sites, but this is not the case (Figure 8b). We thus conclude, as did Grauel et al. (2013), that salinity has no detectable influence on the clumped isotope composition of foraminifera growing at a given temperature.

\subsection{Comparison with previous calibrations}


The only two calibrations directly relevant to foraminifera (Tripati et al., 2010; Grauel et al., 2013) belong to an early period of clumped isotope measurements, where major methodological advances such as the introduction of the "absolute" reference frame of Dennis et al. (2011) were not taken into account. Nevertheless, several of their conclusions (e.g., the lack of detectable species or salinity biases) are fully consistent with our findings, reinforcing the notion that $\Delta_{47}$ values in foraminifera from very different environments appear to be determined exclusively by calcification temperature.

In many cases, the lack of common carbonate standards shared between calibrations studies, as well as the uncertainties associated with acid temperature corrections, preclude precise comparisons between calibration equations from different laboratories. Nevertheless, we note that the slope of Equation 3 is indistinguishable from those obtained in several recent studies based on large numbers of observations on synthetic and natural carbonates covering wide temperature ranges (Bonifacie et al., 2017; Kelson et al., 2017).

We may, however, precisely compare our results to those from other studies provided (i) that they are anchored to the ETH standards (or to internal laboratory standards referenced to the ETH standards), and (ii) that raw data are processed using the IUPAC isotopic parameters of Brand et al. (2010). Here we consider the recently published dataset of Breitenbach et al. (2018) and the tufa/travertine calibration of Kele et al. (2015), which was recently reprocessed by Bernasconi et al. (in review).

Breitenbach et al. (2018) reported $\Delta_{47}$ values of core-top foraminifera, and compared them with a clumped-isotope calibration based on inorganic cave pearls. Their foraminifera data (Figure 9) are generally within error bars of our calibration line, but a large fraction of their samples display $\Delta_{47}$ values $20-35 \mathrm{ppm}$ lower than expected from 
our Equation 3. Most of their observations lie between 10 and $20{ }^{\circ} \mathrm{C}$, with many $\Delta_{47}$ values clustered around $0.68 \%$. The reason for these slightly lower $\Delta_{47}$ values and weaker correlation with temperature remains unclear. Although Breitenbach et al. assigned calcification temperatures based on the WOA database, reprocessing their observations using our oxygen-18 temperature approach does not eliminate the discrepancies between the two studies. Alternatively, the observed differences could result from the use of different cleaning protocols. Breitenbach et al. (2018) included an oxidative step using $5 \% \mathrm{H}_{2} \mathrm{O}_{2}$. Although our cleaning tests (Figure 3 ) imply that the use of $1 \% \mathrm{H}_{2} \mathrm{O}_{2}$ has no detectable isotopic effects, it is conceivable that higher $\mathrm{H}_{2} \mathrm{O}_{2}$ concentrations would slightly bias $\Delta_{47}$ values through cryptic recrystallization at room temperature. More generally, these observations called for future foraminifera intercomparison exercises.

We are also able to compare our results to inorganic calibrations based on tufa and travertines (Kele et al., 2015, reprocessed by Bernasconi et al., in review) and cave pearls (Breitenbach et al., 2018), both of which have been applied to foraminifera (Rodriguez-Sanz et al., 2017; Breitenbach et al., 2018). The three calibrations display virtually identical slopes (Figure 10). Moreover, our results are in full agreement with the Kele et al. (2015) data over the temperature range where they overlap $\left(6-5^{\circ} \mathrm{C}\right)$. The cave pearl calibration predicts slightly lower $\Delta_{47}$ values, possibly consistent with the similar offset seen in Figure 9, resulting in slightly colder temperature estimates (by 2$4.5^{\circ} \mathrm{C}$ between $0{ }^{\circ} \mathrm{C}$ and $25^{\circ} \mathrm{C}$ ), which would be problematic for most paleoceanographic reconstructions. 
Although our regression errors are small enough to meet the requirements of most paleoclimate studies, inter-laboratory comparisons of $\Delta_{47}$ measurements generally remain significantly less precise. In our view, this is primarily due to the lack of common carbonate standards. Because the observations reported here are tightly anchored to the widely distributed carbonate standards ETH-1/2/3, it should be possible to precisely compare our findings to independent $\Delta_{47}$ measurements standardized in the same way, and we anticipate that future studies can fully benefit from our calibration.

\section{CONCLUSION}

We have investigated the relationship between the $\Delta_{47}$ values of foraminifera and calcification temperatures using samples collected in core-tops from different oceanic basins, yielding a robust calibration for temperatures ranging from $-2{ }^{\circ} \mathrm{C}$ to $25{ }^{\circ} \mathrm{C}$. Based on the study of 9 planktonic and 2 benthic foraminiferal species chosen among the most commonly used in paleoclimatology, we conclude that our results confirm the absence of statistically significant species and salinity effects at our precision level, so that $\Delta_{47}$ values in planktonic and benthic foraminifera seem to be exclusively determined by temperature. We found no evidence for detectable size effects on $\Delta_{47}$ over a wide range of sizes in 6 species of planktonic and benthic foraminifera, suggesting that it is possible to combine foraminifera of different size fractions, which should result in notable gains in picking time, total number of analytical replicates and, ultimately, final paleotemperature precision.

Our dataset is indistinguishable from the tufas and travertines calibration of Kele et al. (2015, reprocessed) and generally very close to the cave pearl calibration of Breitenbach et al. (2018), both using common carbonate standards and analytical process. Defining 
optimal standardization procedures to minimize systematic inter-laboratory discrepancies in clumped isotope measurements is a matter of ongoing debate, and so we took care to include a large number of international carbonate standard analyses in the results reported here. Future foraminifer studies using the same carbonate standards should provide an excellent opportunity to test whether this strategy yields a significant improvement in inter-laboratory reproducibility. 


\section{Acknowledgements}

We are grateful to three anonymous reviewers whose comments helped improve the present report. MP thanks Santiago Moreira-Martinez for his training in data processing, Aline Govin and Hervé Guillou for fruitful discussions. MP received a PhD fellowship from CEA (Commissariat à l'Energie Atomique et aux Energies Alternatives, France). All the isotopic analysis as well as the SEM pictures have been performed on equipment belonging to the Analytical Platform PANOPLY (LSCE-GEOPS).

\section{Contributions}

MP selected core-tops, devised and performed the cleaning protocol experiments, picked and cleaned the samples, performed all clumped isotope analyses, and wrote the manuscript. MD and DB assisted with the clumped isotope analyses and co-wrote the manuscript. MD provided guidance in the statistical treatment of data. FD performed and processed traditional stable isotope analyses. NS performed and processed traditional stable isotope analyses and helped with clumped isotope analyses. GI validated foraminifer species identification. JB, FJ, CK, FB, EM, NVR and CW provided access to their respective core and foraminifer collections. FB, EM, NVR and CW contributed substantially to discussions regarding the assignment of independent constraints on calcification temperatures. 


\section{REFERENCES}

Abrantes F., Lebreiro S., Rodrigues T., Gil I., Bartels-Jónsdóttir H., Oliveira P., Kissel C. and Grimalt J. O. (2005) Shallow-marine sediment cores record climate variability and earthquake activity off Lisbon (Portugal) for the last 2000 years. Quat. Sci. Rev. 24, 2477-2494.

Bonifacie M., Calmels D., Eiler J. M., Horita J., Chaduteau C., Vasconcelos C., Agrinier P., Katz A., Passey B. H., Ferry J. M. and Bourrand J. J. (2017) Calibration of the dolomite clumped isotope thermometer from 25 to $350{ }^{\circ} \mathrm{C}$, and implications for a universal calibration for all (Ca, Mg, Fe)CO3carbonates. Geochim. Cosmochim. Acta 200, 255279. Available at: http://dx.doi.org/10.1016/j.gca.2016.11.028.

Brand W. A., Assonov S. S. and Coplen T. B. (2010) Correction for the 170 interference in $\delta(13 \mathrm{C})$ measurements when analyzing CO2 with stable isotope mass spectrometry (IUPAC Technical Report). Pure Appl. Chem. 82, 1719-1733. Available at: https://www.degruyter.com/view/j/pac.2010.82.issue-8/pac-rep-09-01-05/pacrep-09-01-05.xml.

Brassell S.C, Eglinton G, Marlowe I.T, Pflaumann U S. M. (1986) Molecular stratigraphy: a new tool for climatic assessment. Nature 320, 129-133.

Breitenbach S. F. M., Mleneck-Vautravers M. J., Grauel A.-L., Lo L., Bernasconi S. M., Müller I. A., Rolfe J., Greaves M. and Hodell D. A. (2018) Coupled Mg/Ca and clumped isotope analyses of foraminifera provide consis- tent water temperatures Sebastian. Geochim. Cosmochim. Acta.

Broecker W. S. and Olson E. A. (1961) Lamont radiocarbon measurements VIII. Radiocarbon 3, 176-204.

Came R. E., Brand U. and Affek H. P. (2014) Clumped isotope signatures in modern brachiopod carbonate. Chem. Geol. 377, 20-30. Available at: http://dx.doi.org/10.1016/j.chemgeo.2014.04.004.

Coplen T. B. (1996) Editorial : More uncertainty than necessary. 11, 369-370.

Daëron M., Blamart D., Peral M. and Affek H. P. (2016) Absolute isotopic abundance ratios and the accuracy of $\Delta 47$ measurements. Chem. Geol. 442, 83-96. Available at: http://dx.doi.org/10.1016/j.chemgeo.2016.08.014.

Defliese W. F., Hren M. T. and Lohmann K. C. (2015) Compositional and temperature 
effects of phosphoric acid fractionation on $\Delta 47$ analysis and implications for discrepant calibrations. Chem. Geol. 396, 51-60.

Dennis K. J., Affek H. P., Passey B. H., Schrag D. P. and Eiler J. M. (2011) Defining an absolute reference frame for "clumped" isotope studies of CO 2. Geochim. Cosmochim. Acta 75, 7117-7131. Available at: http://dx.doi.org/10.1016/j.gca.2011.09.025.

Dennis K. J. and Schrag D. P. (2010) Clumped isotope thermometry of carbonatites as an indicator of diagenetic alteration. Geochim. Cosmochim. Acta 74, 4110-4122. Available at: http://dx.doi.org/10.1016/j.gca.2010.04.005.

Douglas P. M. J., Affek H. P., Ivany L. C., Houben A. J. P., Sijp W. P., Sluijs A., Schouten S. and Pagani M. (2014) Pronounced zonal heterogeneity in Eocene southern high-latitude sea surface temperatures. Proc. Natl. Acad. Sci. U. S. A. 111, 1-6. Available at: http://www.ncbi.nlm.nih.gov/pubmed/24753570\%5Cnhttp://www.pnas.org/cont ent/111/18/6582.

Duplessy J.-C. (1978) Isotope studies. Clim. Change 3, 47-67.

Duplessy J. C., Bé A. W. H. and Blanc P. L. (1981) Oxygen and carbon isotopic composition and biogeographic distribution of planktonic foraminifera in the Indian Ocean. Palaeogeogr. Palaeoclimatol. Palaeoecol. 33, 9-46.

Durazzi J. T. (1981) Stable-isotope studies of planktonic foraminifera in North Atlantic core tops. Palaeogeogr. Palaeoclimatol. Palaeoecol. 33, 157-172.

Eagle R. A., Eiler J. M., Tripati A. K., Ries J. B., Freitas P. S., Hiebenthal C., Wanamaker A. D., Taviani M., Elliot M., Marenssi S., Nakamura K., Ramirez P. and Roy K. (2013) The influence of temperature and seawater carbonate saturation state on 13C-180 bond ordering in bivalve mollusks. Biogeosciences 10, 4591-4606.

Eiler J.M. (2007) “Clumped-isotope” geochemistry-The study of naturally-occurring, multiply-substituted isotopologues. Earth Planet. Sci. Lett. 262, 309-327.

Eiler J. M. (2011) Paleoclimate reconstruction using carbonate clumped isotope thermometry. Quat. Sci. Rev. 30, 3575-3588.

Emiliani C. (1966) Isotopic Paleotemperatures. Science (80-. ). 154, 851-857. Available at: http://www.jstor.org/stable/1719432.

Epstein S., Buchsbaum R., Lowenstam H. and Urey H. (1951) Geologic History of Sea Water. Geol. Soc. Am. Bull. 62, 417-426.

Fontanier C., MacKensen A., Jorissen F. J., Anschutz P., Licari L. and Griveaud C. (2006) 
Stable oxygen and carbon isotopes of live benthic foraminifera from the Bay of Biscay: Microhabitat impact and seasonal variability. Mar. Micropaleontol. 58, 159183.

Ghosh P., Adkins J., Affek H., Balta B., Guo W., Schauble E. A., Schrag D. and Eiler J. M. (2006) 13C-180 bonds in carbonate minerals: A new kind of paleothermometer. Geochim. Cosmochim. Acta 70, 1439-1456.

Gonfiantini R., Stichler W. and Rozanski K. (1995) STANDARDS AND

INTERCOMPARISON MATERIALS DISTRIBUTED BY THE INTERNATIONAL ATOMIC ENERGY AGENCY FOR STABLE ISOTOPE MEASUREMENTS. IAEA-TECDOC.

Grauel A. L., Schmid T. W., Hu B., Bergami C., Capotondi L., Zhou L. and Bernasconi S. M.

(2013) Calibration and application of the "clumped isotope" thermometer to foraminifera for high-resolution climate reconstructions. Geochim. Cosmochim. Acta 108, 125-140. Available at: http://dx.doi.org/10.1016/j.gca.2012.12.049.

Grubbs F. E. (1969) Procedures for detecting outlying observations in samples.

Technometrics 11, 1-21.

H. Elderfield and G. Ganssen (2000) Past temperature and d180 of surface ocean waters inferred from foraminiferal Mg/Ca ratios. Lett. to Nat. 705, 442-445.

Hadden C. S. and Cherkinsky A. (2015) 14 C Variations in Pre-Bomb Nearshore Habitats of the Florida Panhandle, USA. Radiocarbon 57, 469-479.

Hatté C., Hodgins G., Jull A. J. T., Bishop B. and Tesson B. (2008) Marine chronology based on 14C dating on diatoms proteins. Mar. Chem. 109, 143-151.

Herbert T. D. (2013) Alkenone Paleotemperature Determinations. 2nd ed., Elsevier Ltd. Available at: http://dx.doi.org/10.1016/B978-0-08-095975-7.00615-X.

Hut G. (1987) Consultants' group meeting on stable isotope reference samples for geochemical and hydrological investigations.

Jonkers L. and Ku M. (2015) Global analysis of seasonality in the shell flux of extant planktonic Foraminifera. Biogeosciences, 2207-2226.

Katz A., Bonifacie M., Hermoso M., Cartigny P. and Calmels D. (2017) Laboratory-grown coccoliths exhibit no vital effect in clumped isotope $(\Delta 47)$ composition on a range of geologically relevant temperatures. Geochim. Cosmochim. Acta 208, 335-353.

Kele S., Breitenbach S. F. M., Capezzuoli E., Meckler A. N., Ziegler M., Millan I. M., Kluge T., Deák J., Hanselmann K., John C. M., Yan H., Liu Z. and Bernasconi S. M. (2015) Temperature dependence of oxygen- and clumped isotope fractionation in 
carbonates: A study of travertines and tufas in the $6-95^{\circ} \mathrm{C}$ temperature range. Geochim. Cosmochim. Acta 168, 172-192.

Kelson J. R., Huntington K. W., Schauer A. J., Saenger C. and Lechler A. R. (2017) Toward a universal carbonate clumped isotope calibration: Diverse synthesis and preparatory methods suggest a single temperature relationship. Geochim. Cosmochim. Acta 197, 104-131. Available at: http://dx.doi.org/10.1016/j.gca.2016.10.010.

Kim J.-H., Van der Meer J., Schouten S., Helmke P., Willmott V., Sangiorgi F., Koç N., Hopmans E. C. and Damsté J. S. S. (2010) New indices and calibrations derived from the distribution of crenarchaeal isoprenoid tetraether lipids: Implications for past sea surface temperature reconstructions. Geochim. Cosmochim. Acta 74, 46394654.

Kim J., Schouten S., Hopmans E. C., Donner B. and Damste J. S. S. (2008) Global sediment core-top calibration of the TEX 86 paleothermometer in the ocean. 72, 1154-1173.

Kim S.-T. and O’Neil J. R. (1997) Equilibrium and nonequilibrium oxygen isotope effects in synthetic carbonates. Geochim. Cosmochim. Acta 61, 3461-3475. Available at: http://linkinghub.elsevier.com/retrieve/pii/S0016703797001695.

Kissel C., Laj C., Mulder T., Wandres C. and Cremer M. (2009) The magnetic fraction: A tracer of deep water circulation in the North Atlantic. Earth Planet. Sci. Lett. 288, 444-454. Available at: http://dx.doi.org/10.1016/j.epsl.2009.10.005.

Kissel C., Van Toer A., Laj C., Cortijo E. and Michel E. (2013) Variations in the strength of the North Atlantic bottom water during Holocene. Earth Planet. Sci. Lett. 369, 248259.

Kluge T., John C. M., Jourdan A.-L., Davis S. and Crawshaw J. (2015) Laboratory calibration of the calcium carbonate clumped isotope thermometer in the $25-250^{\circ} \mathrm{C}$ temperature range. Geochim. Cosmochim. Acta 157, 213-227.

Kucera M., Rosell-Melé A., Schneider R., Waelbroeck C. and Weinelt M. (2005) Multiproxy approach for the reconstruction of the glacial ocean surface (MARGO). Quat. Sci. Rev. 24, 813-819.

Lea D. W. (2013) Elemental and Isotopic Proxies of Past Ocean Temperatures. 2nd ed., Elsevier Ltd. Available at: http://dx.doi.org/10.1016/B978-0-08-095975-7.006148.

LeGrande A. N. and Schmidt G. A. (2006) Global gridded data set of the oxygen isotopic 
composition in seawater. Geophys. Res. Lett. 33, 1-5.

Levitt N. P., Eiler J. M., Romanek C. S., Beard B. L. and Johnson C. M. (2018) Near

Equilibrium 13 C - 180 Bonding During Inorganic Calcite Precipitation under

Chemo - Stat Conditions. Geochemistry, Geophys. Geosystems.

Locarnini R. A., Mishonov A. V., Antonov J. I., Boyer T. P., Garcia H. E., Baranova O. K.,

Zweng M. M., Paver C. R., Reagan J. ., Johnson D. R., Hamilton M. and Seidov D.

(2013) NOAA Atlas NESDIS 73 WORLD OCEAN ATLAS 2013 Volume 1:

Temperature. 1. Available at:

http://www.researchgate.net/publication/260389845_NOAA_Atlas_NESDIS_73_W

ORLD_OCEAN_ATLAS_2013_Volume_1_Temperature.

Mangerud J. and Gulliksen S. (1975) Apparent radiocarbon ages of recent marine shells

from Norway, Spitsbergen, and Arctic Canada. Quat. Res. 5, 263-273.

Marchitto T. M., Curry W. B., Lynch-Stieglitz J., Bryan S. P., Cobb K. M. and Lund D. C.

(2014) Improved oxygen isotope temperature calibrations for cosmopolitan

benthic foraminifera. Geochim. Cosmochim. Acta 130, 1-11. Available at:

http://dx.doi.org/10.1016/j.gca.2013.12.034.

Mathien-Blard E. and Bassinot F. (2009) Salinity bias on the foraminifera $\mathrm{Mg} / \mathrm{Ca}$

thermometry: Correction procedure and implications for past ocean hydrographic

reconstructions. Geochemistry, Geophys. Geosystems 10.

McCrea J. M. (1950) On the isotopic chemistry of carbonates and a paleotemperature scale. J. Chem. Phys. 18, 849-857.

Meckler A. N., Ziegler M., Mill??n M. I., Breitenbach S. F. M. and Bernasconi S. M. (2014) Long-term performance of the Kiel carbonate device with a new correction scheme for clumped isotope measurements. Rapid Commun. Mass Spectrom. 28, 1705-1715.

Mix A. C. (1987) Chapter 6 - The oxygen-isotope record of glaciation. v. K-3. eds. W. F.

Ruddiman and H. E. Wright, North America and adjacent oceans during the last deglaciation: Boulde, Colorado, Geological Society of America, The Geology of North America.

Mortyn P. G. and Charles C. D. (2003) Planktonic foraminiferal depth habitat and $\delta 180$ calibrations: Plankton tow results from the Atlantic sector of the Southern Ocean.

Paleoceanography 18, n/a-n/a. Available at:

http://doi.wiley.com/10.1029/2001PA000637.

Müller I. A., Violay M. E. S., Storck J. C., Fernandez A., van Dijk J., Madonna C. and 
Bernasconi S. M. (2017) Clumped isotope fractionation during phosphoric acid digestion of carbonates at $70{ }^{\circ} \mathrm{C}$. Chem. Geol. 449, 1-14.

Müller P. J., Kirst G., Ruhland G., Von Storch I. and Rosell-Melé A. (1998) Calibration of the alkenone paleotemperature index $\mathrm{U} 37 \mathrm{~K}^{\prime}$ based on core-tops from the eastern South Atlantic and the global ocean (60 N-60 S). Geochim. Cosmochim. Acta 62, 1757-1772.

Murray S. T., Arienzo M. M. and Swart P. K. (2016) Determining the $\Delta 47$ acid fractionation in dolomites. Geochim. Cosmochim. Acta 174, 42-53. Available at: http://dx.doi.org/10.1016/j.gca.2015.10.029.

Ortiz D., Mix A. C. and Collier R. W. (1995) Environmental control of living symbiotic and asymbiotic Environmental control of living symbiotic and asymbiotic foraminifera of the California Current. Paleoceanography 10, 987-1009.

Passey B. H. and Henkes G. A. (2012) Carbonate clumped isotope bond reordering and geospeedometry. Earth Planet. Sci. Lett. 351-352, 223-236. Available at: http://dx.doi.org/10.1016/j.epsl.2012.07.021.

Pflaumann U. and Jian Z. (1999) Modern distribution patterns of planktonic foraminifera in the South China Sea and western Pacific : a new transfer technique to estimate regional sea-surface temperatures. Mar. Geol. 156, 41-83.

Reimer P. J., Bard E., Bayliss A., Beck J. W., Blackwell P. G., Ramsey C. B., Buck C. E., Cheng H., Edwards R. L., Friedrich M., Grootes P. M., Guilderson T. P., Haflidason H., Hajdas I., Hatté C., Heaton T. J., Hoffmann D. L., Hogg A. G., Hughen K. A., Kaiser K. F., Kromer B., Manning S. W., Niu M., Reimer R. W., Richards D. A., Scott E. M., Southon J. R., Staff R. A., Turney C. S. M. and van der Plicht J. (2013) IntCal13 and Marine13 Radiocarbon Age Calibration Curves 0-50,000 Years cal BP. Radiocarbon 55, 18691887. Available at:

https://www.cambridge.org/core/product/identifier/S0033822200048864/type/ journal_article.

Roche D. M., Waelbroeck C., Metcalfe B. and Caley T. (2017) FAME (v1 . 0 ): a simple module to simulate the effect of planktonic foraminifer species-specific habitat on their oxygen isotopic content. Geosci. Model Dev. 18, 1-22.

Rodriguez-Sanz L., Bernasconi S. M., Marino G., Heslop D., Müller I. A., Fernandez A., Grant K. M. and Rohling E. J. (2017) Penultimate deglacial warming across the Mediterranean Sea revealed by clumped isotopes in foraminifera. Sci. Rep., 1-11. 
Rogers J. and De Deckker P. (2011) Environmental reconstructions of the upper $500 \mathrm{~m}$ of the southern Indian Ocean over the last 40 ka using Radiolarian (Protista) proxies. Quat. Sci. Rev. 30, 876-886. Available at:

http://dx.doi.org/10.1016/j.quascirev.2011.01.006.

Schauble E. A., Ghosh P. and Eiler J. M. (2006) Preferential formation of 13C-180 bonds in carbonate minerals, estimated using first-principles lattice dynamics. Geochim. Cosmochim. Acta 70, 2510-2529.

Schauer A. J., Kelson J., Saenger C. and Huntington K. W. (2016) Choice of 17 O correction affects clumped isotope ( $\Delta 47$ ) values of CO 2 measured with mass spectrometry. , 2607-2616.

Schiebel R. (2002) Planktic foraminiferal sedimentation and the marine calcite budget. Global Biogeochem. Cycles 16.

Schmiedl G., Pfeilsticker M., Hemleben C. and Mackensen A. (2004) Environmental and biological effects on the stable isotope composition of recent deep-sea benthic foraminifera from the western Mediterranean Sea. Mar. Micropaleontol. 51, 129152.

Schouten S., Hopmans E. C., Schefuß E. and Sinninghe Damsté J. S. (2002) Distributional veriations in marine crenarchaeol membrane lipids: a new tool for reconstructing ancient sea water temperatures? Earth Planet. Sci. Lett. 204, 265-274. Available at: http://www.sciencedirect.com/science/article/pii/S0012821X02009792.

Shackleton N. (1967) Oxygen isotope analyses and Pleistocene temperatures reassessed. Nature 215, 15-17.

Shackleton N.J. (1974) Attainment of isotopic equilibrium between ocean water and the benthonic foraminifera geuns Uvigerina: Isotopic changes in the ocean during the last glacial. Colloq. Int. du C.N.R.S. 219, 203-210.

Sharma S. Das, Patil D. J. and Gopalan K. (2002) Temperature dependence of oxygen isotope fractionation of $\mathrm{CO} 2$ from magnesite-phosphoric acid reaction. Geochim. Cosmochim. Acta 66, 589-593.

Simstich J., Sarnthein M. and Erlenkeuser H. (2003) Paired $\delta 180$ signals of Neogloboquadrina pachyderma (s) and Turborotalita quinqueloba show thermal stratification structure in Nordic Seas. Mar. Micropaleontol. 48, 107-125.

Southon J., Kashgarian M., Fontugne M., Metivier B. and Yim W. W. S. (2002) Marine reservoir corrections for the Indian Ocean and Southeast Asia. Radiocarbon 44, 
167-180.

Squire P., Joannes-Boyau R., Scheffers A. M., Nothdurft L. D., Hua Q., Collins L. B., Scheffers S. R. and Zhao J. (2013) A marine reservoir correction for the HoutmanAbrolhos archipelago, east Indian Ocean, Western Australia. Radiocarbon 55, 103 114.

Stefansky W. (1972) Rejecting outliers in factorial designs. Technometrics 14, 469-479.

Stolper D. A. and Eiler J. M. (2016) Constraints on the formation and diagenesis of phosphorites using carbonate clumped isotopes. Geochim. Cosmochim. Acta 181, 238-259.

Stuiver M., Reimer P. J. and Reimer R. W. (2017) CALIB 7.1 [WWW program] at http://calib. org. Last accessed, 8-24.

Tang J., Dietzel M., Fernandez A., Tripati A. K. and Rosenheim B. E. (2014) Evaluation of kinetic effects on clumped isotope fractionation $(\delta 47)$ during inorganic calcite precipitation. Geochim. Cosmochim. Acta 134,120-136. Available at: http://dx.doi.org/10.1016/j.gca.2014.03.005.

Thiagarajan N., Adkins J. and Eiler J. (2011) Carbonate clumped isotope thermometry of deep-sea corals and implications for vital effects. Geochim. Cosmochim. Acta 75, 4416-4425. Available at: http://dx.doi.org/10.1016/j.gca.2011.05.004.

Tisnérat-Laborde N., Poupeau J.J., Tanau J. F. and Paterne M. (2001) DEVELOPMENT OF A SEMI-AUTOMATED SYSTEM FOR ROUTINE PREPARATION OF CARBONATE SAMPLES. 17th Int. 14C Conf. 43, 299-304.

Tolderlund D. S. and Bé A. W. H. (1971) Seasonal distribution of planktonic foraminifera in the western North Atlantic. Micropaleontology, 297-329.

Tripati A. K., Eagle R. A., Thiagarajan N., Gagnon A. C., Bauch H., Halloran P. R. and Eiler J. M. (2010) 13C-180 isotope signatures and "clumped isotope" thermometry in foraminifera and coccoliths. Geochim. Cosmochim. Acta 74, 5697-5717. Available at: http://dx.doi.org/10.1016/j.gca.2010.07.006.

Tripati A. K., Hill P. S., Eagle R. A., Mosenfelder J. L., Tang J., Schauble E. A., Eiler J. M., Zeebe R. E., Uchikawa J., Coplen T. B., Ries J. B. and Henry D. (2015) Beyond temperature: Clumped isotope signatures in dissolved inorganic carbon species and the influence of solution chemistry on carbonate mineral composition. Geochim. Cosmochim. Acta 166, 344-371. Available at: http://dx.doi.org/10.1016/j.gca.2015.06.021. 
Urey H. C. (1947) The thermodynamic properties of isotopic substances. J. Chem. Soc., 562-581. Available at: http://dx.doi.org/10.1039/JR9470000562.

Vázquez Riveiros N., Govin A., Waelbroeck C., Mackensen A., Michel E., Moreira S., Bouinot T., Caillon N., Orgun A. and Brandon M. (2016) Mg/Ca thermometry in planktic foraminifera: Improving paleotemperature estimations for G. bulloides and N. pachyderma left. Geochemistry, Geophys. Geosystems 17, 1249-1264. Available at: http://dx.doi.org/10.1002/2015GC006234.

Wacker U., Fiebig J., Tödter J., Schöne B. R., Bahr A., Friedrich O., Tötken T., Gischler E. and Joachimski M. M. (2014) Empirical calibration of the clumped isotope paleothermometer using calcites of various origins. Geochim. Cosmochim. Acta 141, 127-144.

Walker D. A., Linton A. E. and Schafer C. T. (1974) Sudan Black B; a superior stain to Rose Bengal for distinguishing living from non-living foraminifera. J. Foraminifer. Res. 4, 205-215.

York D., Evensen N. M., Martínez M. L. and De Basabe Delgado J. (2004) Unified equations for the slope, intercept, and standard errors of the best straight line. Am. J. Phys. 72, 367-375. Available at: http://aapt.scitation.org/doi/10.1119/1.1632486.

Zaarur S., Affek H. P. and Brandon M. T. (2013) A revised calibration of the clumped isotope thermometer. Earth Planet. Sci. Lett. 382, 47-57. Available at: http://dx.doi.org/10.1016/j.epsl.2013.07.026.

Zaarur S., Olack G. and Affek H. P. (2011) Paleo-environmental implication of clumped isotopes in land snail shells. Geochim. Cosmochim. Acta 75, 6859-6869.

Zhang Y. G., Pagani M. and Wang Z. (2016) Ring Index: A new strategy to evaluate the integrity of TEX86paleothermometry. Paleoceanography 31, 220-232.

Zweng M. M., Reagan J. R., Antonov J. I., Locarnini R. A., Mishonov A. V, Boyer T. P., Garcia H. E., Baranova O. K., Johnson D. R. and Seidov D. (2013) World ocean atlas 2013. Volume 2, Salinity. 


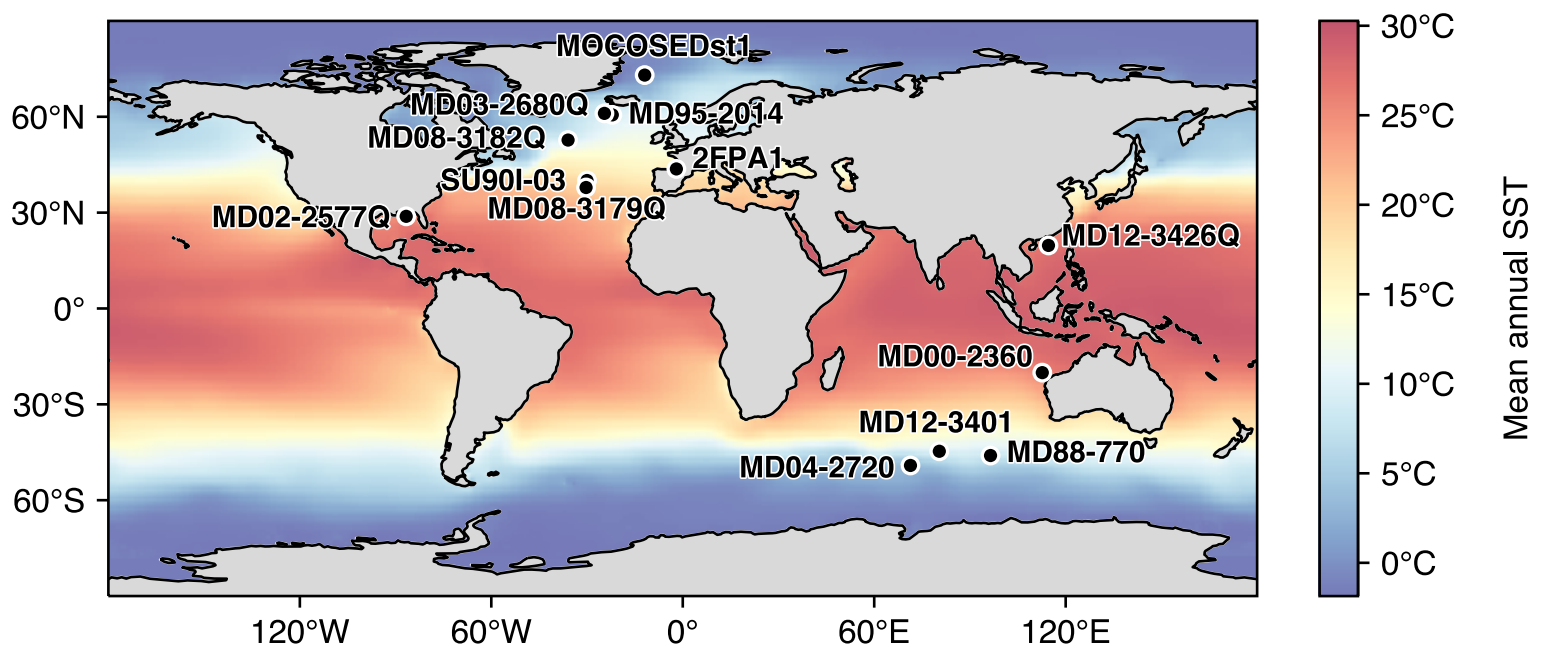

Figure 1: Map of core-top location used to establish this calibration, with the mean annual SST from WOA13. 


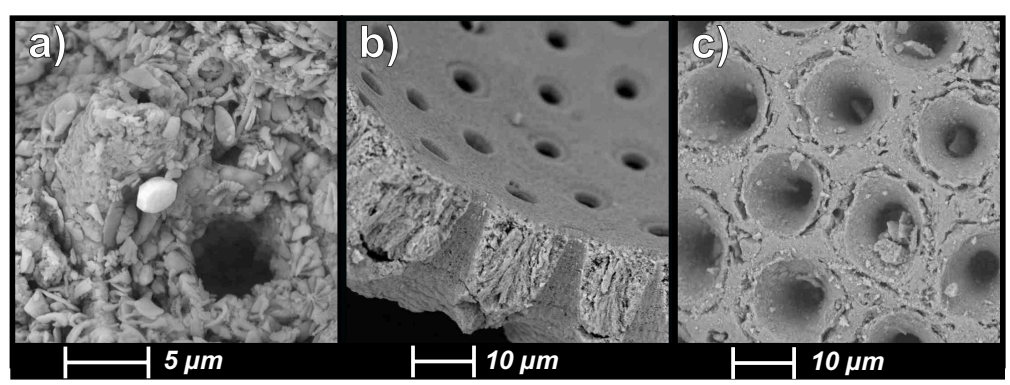

Figure 2: Scanning Electron Microscopy (SEM) pictures of G. ruber shells: a) before cleaning, b) after cleaning using the protocol of Grauel et al., 2013; and c) after cleaning using the protocol of Tripati et al., 2010. 


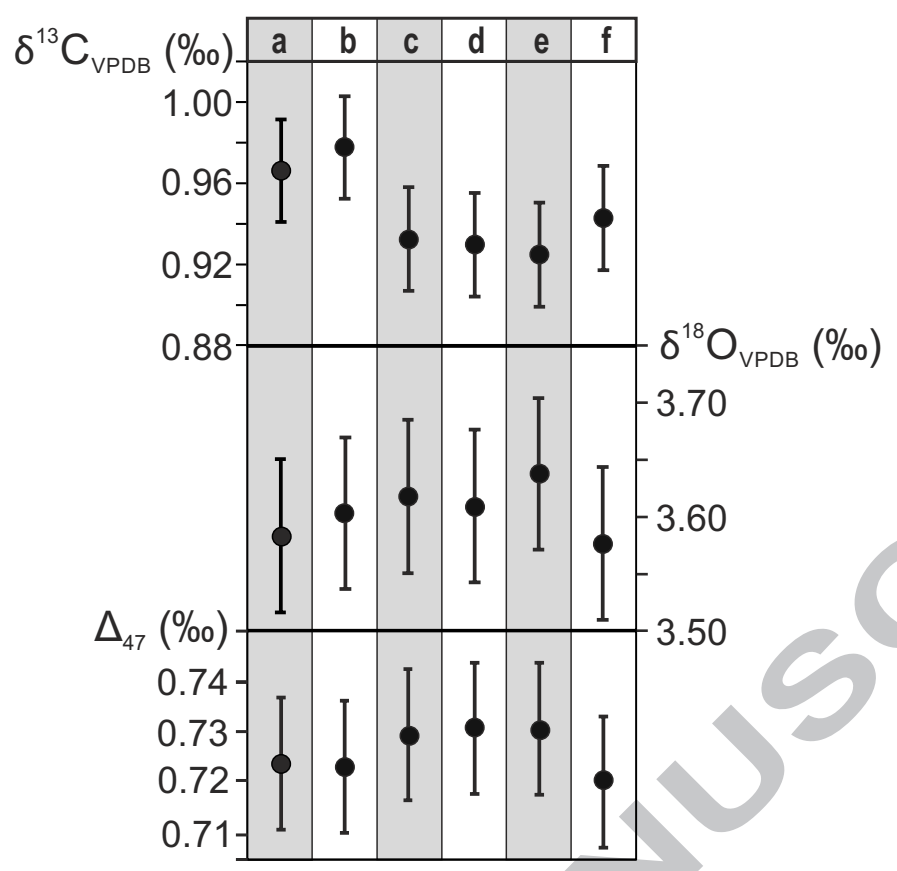

Figure 3: $\delta^{13} \mathrm{C}, \delta^{18} \mathrm{O}$ and $\Delta_{47}$ values (2SE) of Elphidium crispium obtained after: (a) cleaning protocol of Grauel et al., 2013 in grey bands; (b) cleaning protocol of Tripati et al., 2010 in white bands; (c) 15 days in ethanol followed by (a); (d) 15 days in ethanol followed by (b); (e) 15 days in ethanol and Rose Bengal followed by (a); and (f) 15 days in ethanol and Rose Bengal followed by (b). 


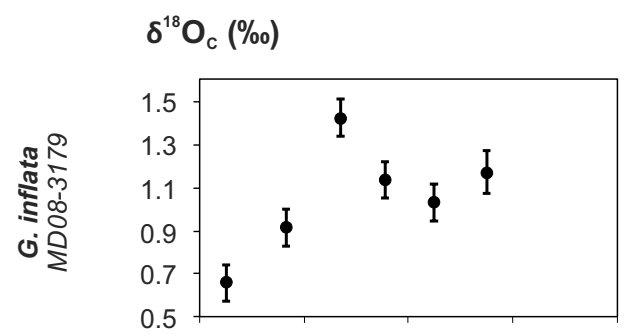

$\Delta_{47}(\%)$
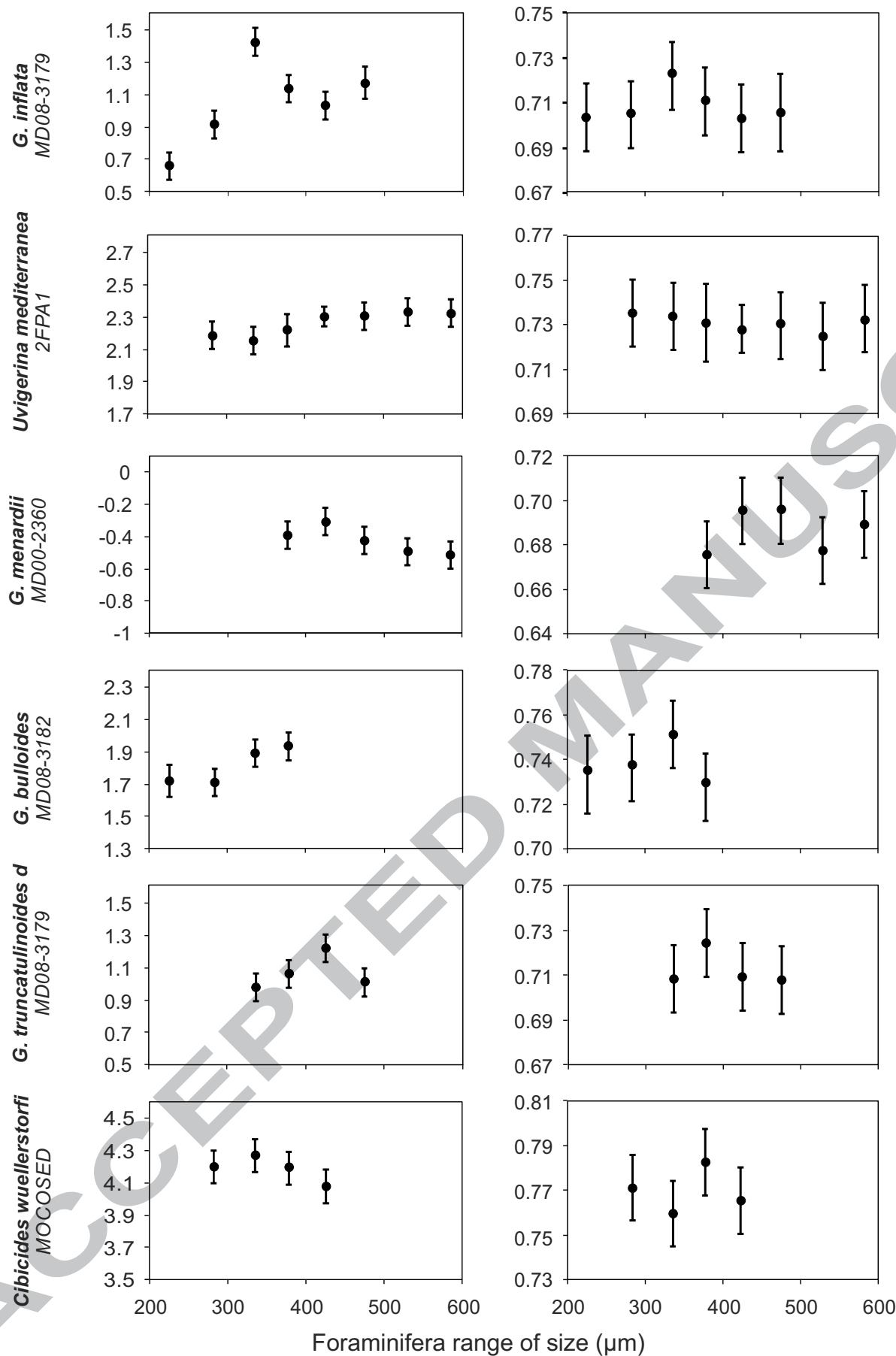

Figure 4: $\delta^{18} \mathrm{O}$ and $\Delta_{47}$ values (2SE) of six foraminifera species for different size fractions. 

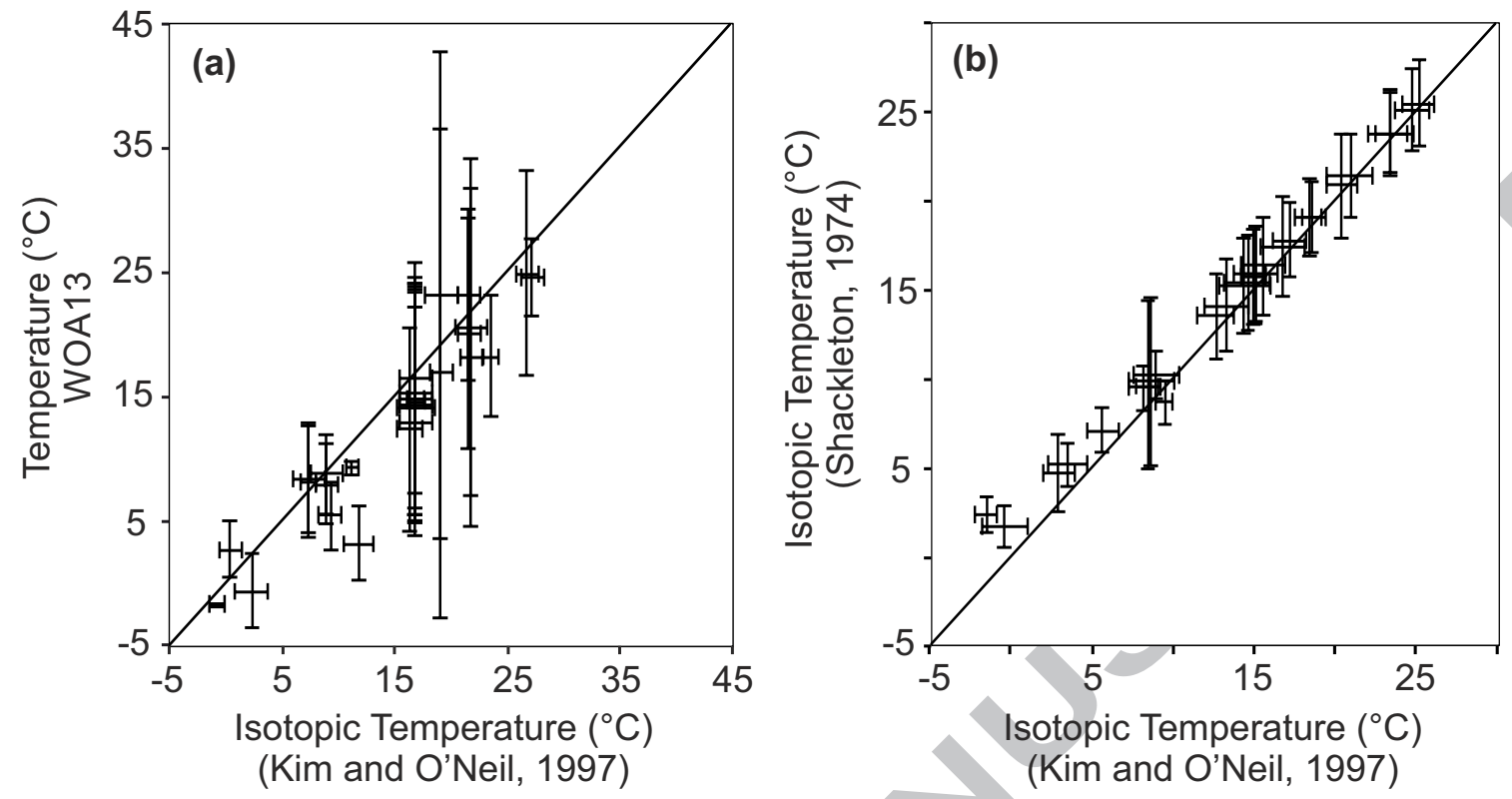

Figure 5: Independent temperature comparison from (a) WOA13 and oxygen isotopic data using the Kim and O'Neil (1997) equation and (b) oxygen isotopic temperatures computed with Shackleton (1974) and Kim and O’Neil (1997) equations. 


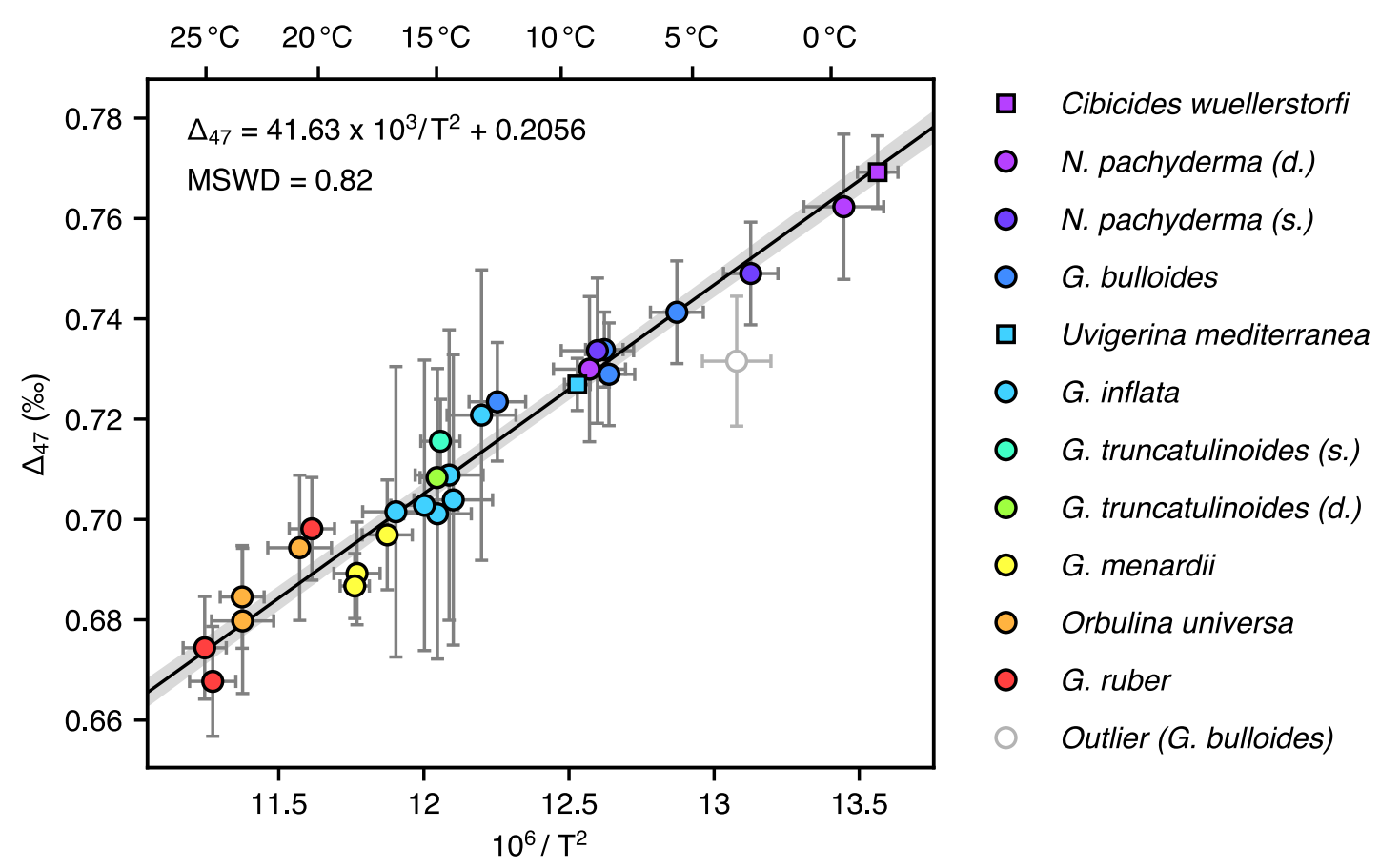

Figure 6: $\Delta_{47}$ values (mean and 2SE) compared to isotopic temperatures (mean and 2SE) obtained with Kim and O’Neil, 1997 for planktonic (circle) and benthic (square) foraminifera samples, combining all size fraction. The calibration regression (black line) is calculated following York et al. (2004) with $95 \%$ confidence level (grey band). 


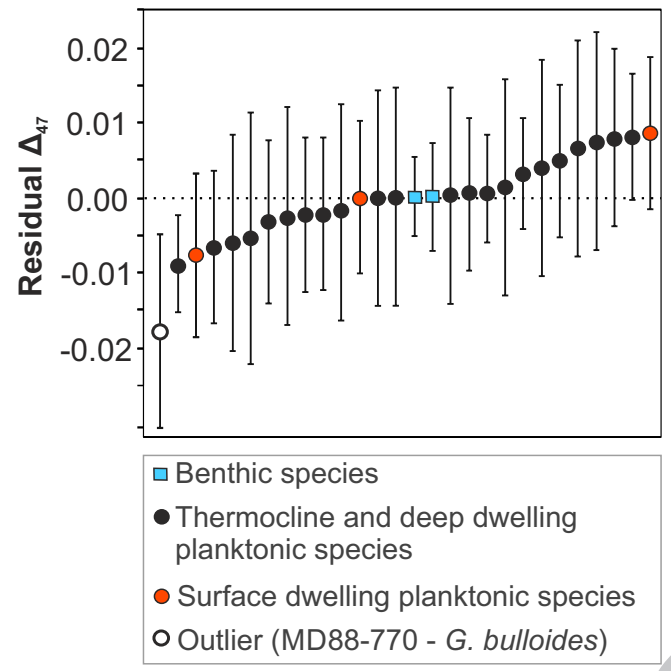

Figure 7: $\Delta_{47}$ residuals (2SE) for benthic foraminifera (blue square), surface dwelling planktonic foraminifera (red circles) and thermocline and deep dwelling planktonic species (black circles) ranged by growing residual. Outlier sample (white circle) is included for comparison. 

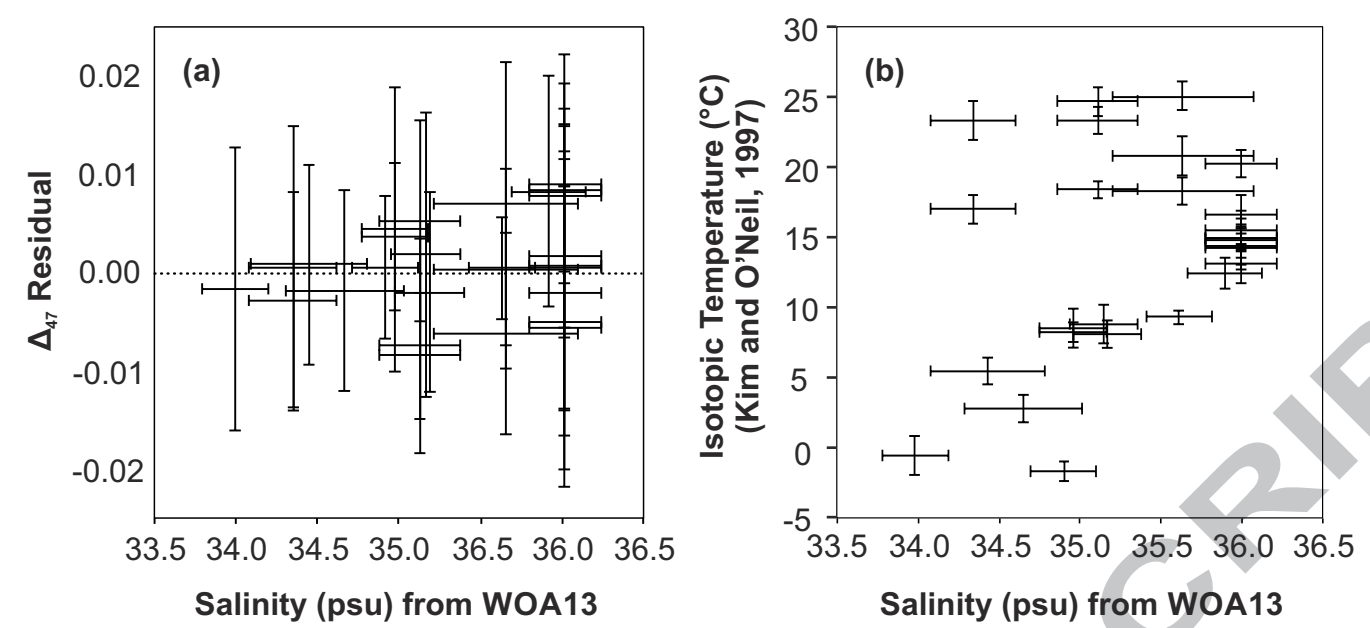

Figure 8: (a) $\Delta_{47}$ residuals (2SE) and (b) temperature derived from Kim and O'Neil, (1997), both compared to salinity, for each species and core-top location. 


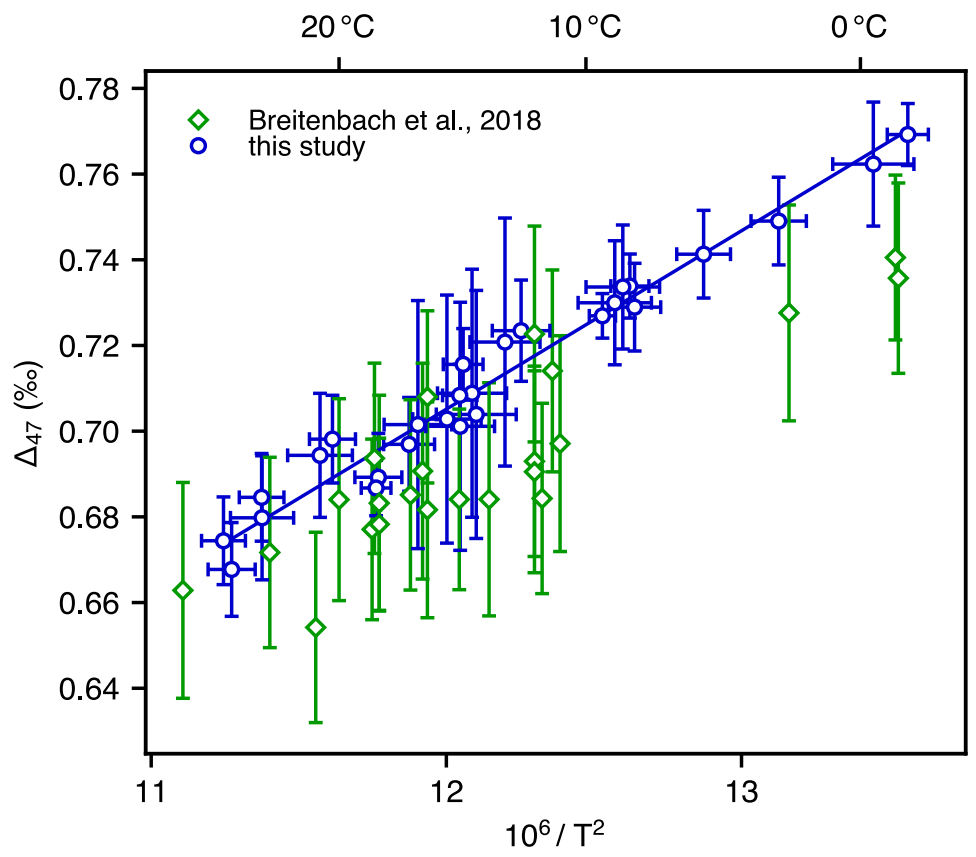

Figure 9: Comparison of our foraminifer $\Delta_{47}$-temperature calibration in blue dots (95\% confidence) with the foraminifer dataset from Breitenbach et al. (2018) in green diamonds (uncertainties at 2SE). 


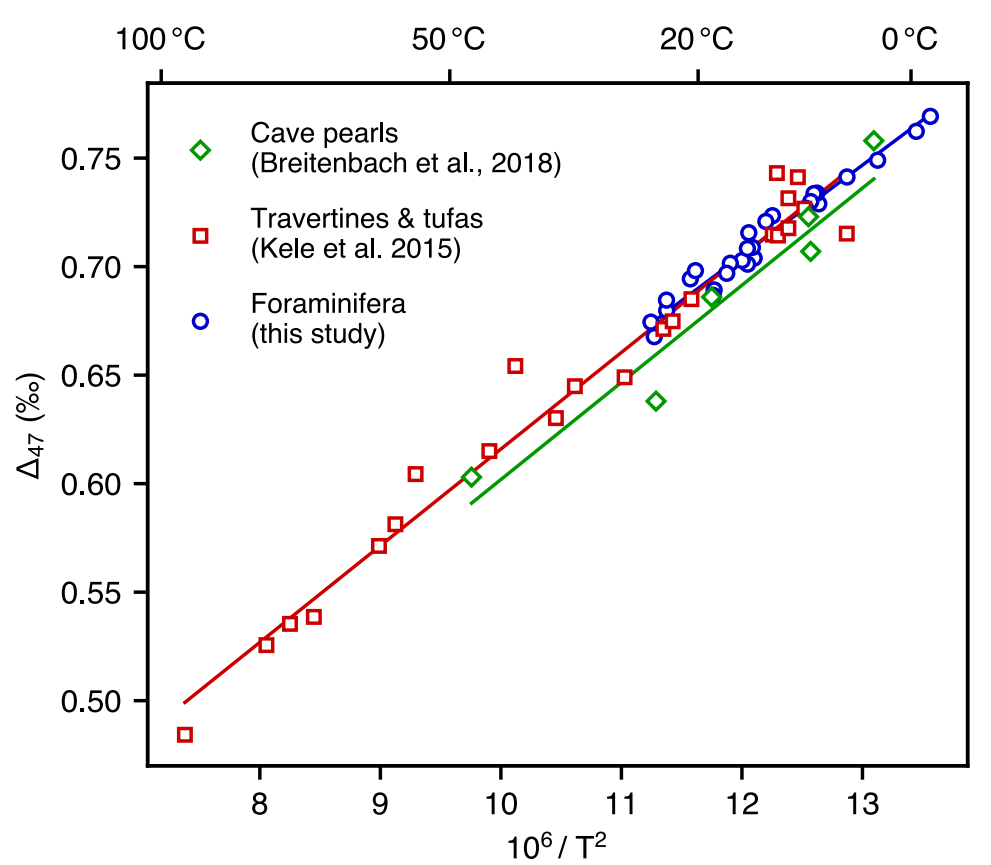

Figure 10: Comparison of our foraminifer $\Delta_{47}$ - temperature calibration in blue dots with the cave pearl calibration of Breitenbach et al. (2018) in green diamonds and the travertines and tufas calibration of Kele et al. (2015), recalculated by Bernasconi et al. (in review) using the parameters recommended by Daëron et al. (2016) in red squares. 
Table 1: Core top locations and water depths with species considered in our calibration and chronological constraints. listing from cooler to warmer temperatures defined using Kim and O’Neil (1997).

\begin{tabular}{|c|c|c|c|c|c|c|c|}
\hline Core & $\begin{array}{l}\text { Latitude } \\
\qquad\left({ }^{\circ} \mathbf{N}\right)\end{array}$ & Longitude $\left({ }^{\circ} \mathbf{E}\right)$ & $\begin{array}{l}\text { Water depth } \\
\text { (m) }\end{array}$ & Species & $\begin{array}{l}\text { Core-top } \\
\text { cal. yrs BP } \\
(95 \% \text { CL) }\end{array}$ & $\begin{array}{l}\text { Reservoir } 14 C \text { age } \\
\quad(y r . \pm 1 \sigma)\end{array}$ & References \\
\hline MOCOSEDst1 & 73.04 & -11.93 & 1839 & $\frac{\text { Cibicides wuellerstorfi; }}{N . \text { pachyderma } \mathrm{s}}$ & $6317(+150 /-94)$ & (a) & (1) \\
\hline MD04-2720 & -49.13 & 71.36 & 750 & N. pachyderma $\mathrm{d}$ & n.a. & & \\
\hline MD88-770 & -46.02 & 96.45 & 3290 & G. bulloides & $6158 *( \pm 120)$ & $\bar{\gamma}$ & $(2-3)$ \\
\hline MD12-3401 & -44.69 & 80.4 & 3445 & G. bulloides & $<4000 * *$ & & (4) \\
\hline MD95-2014 & 60.59 & -22.08 & 2397 & $\underline{\text { G. bulloides }}$ & $715(+94 /-149)$ & $502 \pm 52^{(b)}$ & (1) \\
\hline MD08-3182Q & 52.71 & -35.94 & 1355 & N. pachyderma s; G. bulloides & $500(+40 /-53)$ & & (5) \\
\hline MD03-2680Q & 61.06 & -24.55 & 1812 & N. pachyderma $\mathrm{d}$ & 402 & & (6) \\
\hline 2FPA1 & 43.67 & -2.00 & 664 & Uvigerina mediterranea & $<4000 * * *$ & & $(1)$ \\
\hline SU90I-03 & 40.05 & -30 & 2475 & $\underline{\text { G. bulloides }}$ & $2013(+125 /-120)$ & $401 \pm 34^{(\mathrm{c})}$ & (1) \\
\hline MD08-3179Q & 37.86 & -30.3 & 2036 & $\begin{array}{l}\text { G. ruber; } \underline{\text { G. inflata; }} \\
\text { G. truncatulinoides s; } \\
\text { G. truncatulinoides d }\end{array}$ & $4403(+153 /-121)$ & $401 \pm 34^{(\mathrm{c})}$ & (1) \\
\hline MD12-3426Q & 19.73 & 114.61 & 3630 & G. menardii; O. universa & $1755(+159 /-139)$ & $341 \pm 50^{(\mathrm{d})}$ & (1) \\
\hline MD00-2360 & -20.08 & 112.67 & 980 & $\begin{array}{l}\text { G. menardii, } \text { O. universa; } \\
\text { G. ruber }\end{array}$ & $3622(+135 /-137)$ & $466 \pm 31^{(\mathrm{e})}$ & (1) \\
\hline MD02-2577Q & 28.84 & -86.67 & 4076 & $\begin{array}{c}\text { G. menardii; O. universa; } \\
\text { G. ruber }\end{array}$ & $1107(+110 /-105)$ & $318 \pm 21^{(\mathrm{f})}$ & (1) \\
\hline
\end{tabular}

* Age determined at $21 \mathrm{~cm}$ in the core

** Age determined by stratigraphic control

*** Age determined by presence of Rose Bengal

(1) This study; (2) Hatté et al. 2008; (3) Rogers and De Deckker 2011; (4) Vázquez Riveiros et al. 2016; (5) Kissel et al. 2013 and (6) Kissel et al. 2009

(a) Mangerud and Gulliksen 1975; (b) Broecke and Olson 1961; (c) Abrantes et al. 2005; (d) Southon et al. 2002; (e) Squire et al. 2013 and (f) Hadden and Cherkinsky 2015. 
Species used for AMS radiocarbon dating 
Table 2: $\delta^{18} \mathrm{O}_{\mathrm{VPDB}}$ and $\Delta_{7}$ values for different size ranges within each species.

\begin{tabular}{|c|c|c|c|c|c|c|}
\hline $\begin{array}{l}\text { Cores and } \\
\text { Species }\end{array}$ & $\begin{array}{c}\text { Size } \\
\text { fraction } \\
(\mu \mathrm{m})\end{array}$ & $\mathbf{N}^{*}$ & $\begin{array}{c}\delta^{18} \mathrm{O}_{\mathrm{VPDB}} \\
(\%)\end{array}$ & $\mathrm{SE}^{* *}$ & $\Delta_{47}(\% 0)$ & $\mathbf{S E} * *$ \\
\hline \multirow{7}{*}{$\begin{array}{c}\text { Uvigerina } \\
\text { mediterranea }\end{array}$} & $250-315$ & 4 & 2.18 & 0.04 & 0.732 & 0.007 \\
\hline & $315-355$ & 4 & 2.14 & 0.04 & 0.730 & 0.007 \\
\hline & $355-400$ & 3 & 2.21 & 0.05 & 0.727 & 0.009 \\
\hline & $400-450$ & 8 & 2.29 & 0.03 & 0.725 & 0.005 \\
\hline & $450-500$ & 4 & 2.29 & 0.04 & 0.726 & 0.007 \\
\hline & $500-560$ & 4 & 2.32 & 0.04 & 0.721 & 0.007 \\
\hline & $>560$ & 4 & 2.31 & 0.04 & 0.729 & 0.007 \\
\hline MD00-2360 & $355-400$ & 4 & -0.41 & 0.04 & 0.675 & 0.007 \\
\hline \multirow[t]{4}{*}{ G. menardii } & $400-450$ & 4 & -0.32 & 0.04 & 0.696 & 0.007 \\
\hline & $450-500$ & 4 & -0.44 & 0.04 & 0.696 & 0.007 \\
\hline & $500-560$ & 4 & -0.51 & 0.04 & 0.677 & 0.007 \\
\hline & $>560$ & 4 & -0.53 & 0.04 & 0.689 & 0.007 \\
\hline MD08-3179 & $200-250$ & 4 & 0.65 & 0.04 & 0.702 & 0.007 \\
\hline \multirow[t]{5}{*}{ G. inflata } & $250-315$ & 4 & 0.90 & 0.04 & 0.703 & 0.007 \\
\hline & $315-355$ & 4 & 1.41 & 0.04 & 0.721 & 0.007 \\
\hline & $355-400$ & 4 & 1.12 & 0.04 & 0.709 & 0.007 \\
\hline & $400-450$ & 4 & 1.02 & 0.04 & 0.701 & 0.007 \\
\hline & $450-500$ & 3 & 1.16 & 0.05 & 0.704 & 0.009 \\
\hline MD08-3179 & $315-355$ & 4 & 0.98 & 0.04 & 0.704 & 0.007 \\
\hline \multirow{3}{*}{$\begin{array}{l}\text { G. truncatulinoides } \\
\text { (d.) }\end{array}$} & $355-400$ & 4 & 0.99 & 0.04 & 0.721 & 0.007 \\
\hline & $400-450$ & 4 & 1.07 & 0.04 & 0.705 & 0.007 \\
\hline & $450-500$ & 4 & 1.03 & 0.04 & 0.703 & 0.007 \\
\hline MD08-3182 & $200-250$ & 3 & 1.77 & 0.05 & 0.730 & 0.009 \\
\hline \multirow[t]{3}{*}{ G. bulloides } & $250-315$ & 4 & 1.71 & 0.04 & 0.733 & 0.007 \\
\hline & $315-355$ & 4 & 1.79 & 0.04 & 0.748 & 0.007 \\
\hline & $355-400$ & 4 & 1.77 & 0.04 & 0.724 & 0.007 \\
\hline \multirow{4}{*}{$\begin{array}{l}\text { MOCOSED } \\
\text { Cibicides } \\
\text { wuellerstorfi }\end{array}$} & $250-315$ & 4 & 4.07 & 0.04 & 0.771 & 0.007 \\
\hline & $315-355$ & 4 & 4.13 & 0.04 & 0.759 & 0.007 \\
\hline & $355-400$ & 4 & 4.06 & 0.04 & 0.783 & 0.007 \\
\hline & $400-450$ & 4 & 3.97 & 0.04 & 0.765 & 0.007 \\
\hline
\end{tabular}

* $\mathrm{N}$ : number of replicates

** $\mathrm{SE}=$ standard error 
Table 3: $\delta^{8} \mathrm{O}$ and $\Delta_{4}$ compositions of each samples with corresponding average $\delta^{8} \mathrm{O}$ of seawater and three different estimates of calcification temperature respectively based on WOA13. Shackleton (1974) and Kim and O’Neil (1997).

\begin{tabular}{|c|c|c|c|c|c|c|c|c|c|c|c|c|c|c|c|}
\hline Core & Species & $\begin{array}{c}\mathrm{FCD}(\mathrm{m}) \\
*\end{array}$ & $\mathrm{~N}^{*}$ & $\begin{array}{l}\text { d180sw (\%o } \\
\text { VSMOW) }\end{array}$ & $\mathrm{SE} * *$ & $\begin{array}{l}\text { d180c (\%o } \\
\text { VPDB) }\end{array}$ & $\mathrm{SE}^{* *}$ & $\begin{array}{c}\text { T WOA13 } \\
\left({ }^{\circ} \mathrm{C}\right)\end{array}$ & $S D^{* *}$ & $\begin{array}{c}\text { T S74 } \\
\left({ }^{\circ} \mathrm{C}\right)\end{array}$ & $\mathrm{SE}^{* *}$ & $\begin{array}{c}\text { T K97 } \\
\left({ }^{\circ} \mathrm{C}\right)\end{array}$ & $\mathrm{SE}^{* *}$ & $\Delta 47$ (\%о) & $\mathrm{SE}^{* *}$ \\
\hline MOCOSED & Cibicides wuellerstorfi & 1839 & 16 & 0.27 & 0.20 & 4.06 & 0.02 & -0.9 & 0.1 & 2.5 & 0.5 & -1.6 & 0.4 & 0.7692 & 0.0037 \\
\hline MD04-2720 & N. pachyderma (d.) & $0-300$ & 4 & -0.34 & 0.21 & 3.16 & 0.04 & 2.0 & 1.6 & 1.8 & 0.6 & -0.4 & 0.7 & 0.7623 & 0.0074 \\
\hline MOCOSED & N. pachyderma (s.) & $0-300$ & 8 & 0.10 & 0.28 & 2.80 & 0.03 & 0.2 & 1.2 & 4.8 & 1.1 & 2.9 & 0.5 & 0.7490 & 0.0052 \\
\hline MD88-770 & G. bulloides & $0-300$ & 5 & -0.24 & 0.20 & 2.34 & 0.04 & 11.1 & 1.5 & 5.2 & 0.6 & 3.4 & 0.6 & 0.7316 & 0.0066 \\
\hline MD12-3401 & G. bulloides & $0-300$ & 8 & -0.15 & 0.21 & 1.91 & 0.03 & 8.7 & 1.4 & 7.2 & 0.7 & 5.6 & 0.5 & 0.7413 & 0.0052 \\
\hline MD95-2014 & G. bulloides & $0-300$ & 8 & 0.39 & 0.20 & 1.86 & 0.03 & 8.3 & 1.6 & 9.6 & 0.7 & 8.1 & 0.5 & 0.7289 & 0.0052 \\
\hline MD08-3182 & G. bulloides & $0-300$ & 15 & 0.33 & 0.38 & 1.76 & 0.02 & 6.8 & 2.3 & 9.7 & 2.4 & 8.3 & 0.4 & 0.7339 & 0.0038 \\
\hline MD08-3182 & N. pachyderma (s.) & $0-300$ & 4 & 0.33 & 0.38 & 1.70 & 0.04 & 6.8 & 2.3 & 10.0 & 2.4 & 8.6 & 0.7 & 0.7336 & 0.0074 \\
\hline MD03-2680 & N. pachyderma (d.) & $0-300$ & 4 & 0.36 & 0.20 & 1.66 & 0.04 & 8.3 & 1.6 & 10.3 & 0.7 & 8.9 & 0.7 & 0.7300 & 0.0074 \\
\hline 2FPA1 & Uvigerina mediterranea & 664 & 31 & 0.59 & 0.20 & 2.26 & 0.02 & 10.6 & 0.3 & 8.8 & 0.6 & 9.4 & 0.3 & 0.7269 & 0.0027 \\
\hline SU90-03 & G. bulloides & $0-300$ & 6 & 1.07 & 0.26 & 1.56 & 0.04 & 15.4 & 4.2 & 13.6 & 1.2 & 12.5 & 0.6 & 0.7234 & 0.0060 \\
\hline MD08-3179 & G. inflata $315-355 \mu \mathrm{m}$ & $0-300$ & 4 & 1.07 & 0.27 & 1.41 & 0.04 & 15.9 & 4.8 & 14.2 & 1.3 & 13.2 & 0.7 & 0.7208 & 0.0074 \\
\hline MD08-3179 & G. inflata $450-500 \mu \mathrm{m}$ & $0-300$ & 3 & 1.07 & 0.27 & 1.16 & 0.05 & 15.9 & 4.8 & 15.3 & 1.4 & 14.3 & 0.8 & 0.7039 & 0.0085 \\
\hline MD08-3179 & G. inflata $355-400$ & $0-300$ & 4 & 1.07 & 0.27 & 1.12 & 0.04 & 15.9 & 4.8 & 15.5 & 1.4 & 14.5 & 0.7 & 0.7088 & 0.0074 \\
\hline MD08-3179 & G. truncatulinoides (s.) & $0-300$ & 12 & 1.07 & 0.27 & 1.05 & 0.03 & 15.9 & 4.8 & 15.8 & 1.4 & 14.8 & 0.4 & 0.7156 & 0.0043 \\
\hline MD08-3179 & G. inflata $400-450 \mu \mathrm{m}$ & $0-300$ & 4 & 1.07 & 0.27 & 1.02 & 0.04 & 15.9 & 4.8 & 15.9 & 1.4 & 15.0 & 0.7 & 0.7011 & 0.0074 \\
\hline MD08-3179 & G. truncatulinoides (d.) & $0-300$ & 16 & 1.07 & 0.27 & 1.02 & 0.02 & 15.9 & 4.8 & 15.9 & 1.4 & 15.0 & 0.4 & 0.7083 & 0.0037 \\
\hline MD08-3179 & G. inflata $250-315 \mu \mathrm{m}$ & $0-300$ & 4 & 1.07 & 0.27 & 0.90 & 0.04 & 15.9 & 4.8 & 16.4 & 1.4 & 15.5 & 0.7 & 0.7028 & 0.0074 \\
\hline MD08-3179 & G. inflata $200-250 \mu \mathrm{m}$ & $0-300$ & 4 & 1.07 & 0.27 & 0.65 & 0.04 & 15.9 & 4.8 & 17.6 & 1.4 & 16.7 & 0.7 & 0.7015 & 0.0074 \\
\hline MD12-3426 & G. menardii menardi & $0-200$ & 7 & 0.10 & 0.23 & -0.40 & 0.03 & 18.1 & 10.1 & 17.9 & 1.1 & 17.1 & 0.5 & 0.6969 & 0.0056 \\
\hline MD02-2577 & G. menardii menardi & $0-300$ & 8 & 0.76 & 0.23 & -0.01 & 0.03 & 20.6 & 7.0 & 19.1 & 1.1 & 18.3 & 0.5 & 0.6892 & 0.0052 \\
\hline MD00-2360 & G. menardii menardi & $0-200$ & 20 & 0.35 & 0.23 & -0.44 & 0.02 & 22.4 & 2.5 & 19.2 & 1.0 & 18.4 & 0.3 & 0.6867 & 0.0033 \\
\hline MD08-3179 & G. ruber & $0-10$ & 8 & 1.07 & 0.27 & -0.11 & 0.03 & 20.4 & 4.8 & 21.0 & 1.5 & 20.3 & 0.5 & 0.6981 & 0.0052 \\
\hline MD02-2577 & Orbulina universa & $0-200$ & 4 & 0.76 & 0.23 & -0.53 & 0.04 & 20.6 & 7.0 & 21.5 & 1.2 & 20.8 & 0.7 & 0.6944 & 0.0074 \\
\hline MD12-3426 & Orbulina universa & $0-200$ & 4 & 0.10 & 0.23 & -1.71 & 0.04 & 18.1 & 10.1 & 23.9 & 1.2 & 23.3 & 0.7 & 0.6798 & 0.0074 \\
\hline MD00-2360 & Orbulina universa & $0-300$ & 8 & 0.35 & 0.23 & -1.47 & 0.03 & 20.4 & 3.5 & 23.9 & 1.1 & 23.4 & 0.5 & 0.6846 & 0.0052 \\
\hline MD00-2360 & G. ruber & $0-10$ & 7 & 0.35 & 0.23 & -1.74 & 0.03 & 25.8 & 1.6 & 25.2 & 1.2 & 24.7 & 0.5 & 0.6677 & 0.0056 \\
\hline
\end{tabular}


MD02-2577

G. ruber

0-10 8

$0.76 \quad 0.23$

$-1.40$

$\begin{array}{lll}0.03 \quad 25.4 & 4.2\end{array}$

25.5

* FCD: Foraminiferal Calcification Depth, N: number of replicates ** SD = standard deviation $-\mathrm{SE}=$ standard error 